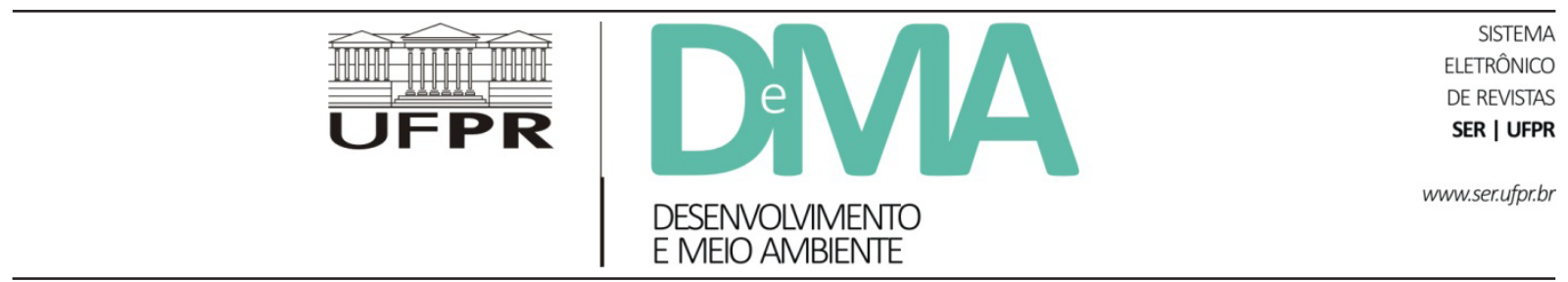

\title{
Vulnerabilidade física de parte do litoral leste do Ceará à erosão
}

\section{Physical Vulnerability of Part of the East Coast of Ceará to the Erosion}

\author{
Márcia Thelma Rios Donato MARINO ${ }^{*}$, Denise FERNANDES ${ }^{1}$, Suellen Galvão MORAES ${ }^{1}$, Adriana Araújo \\ TAJRA $^{2}$ \\ ${ }^{1}$ Universidade de Fortaleza (UNIFOR), Fortaleza, CE, Brasil. \\ ${ }^{2}$ Instituto Camillo Filho (ICF), Teresina, PI, Brasil. \\ *E-mail de contato: marino@unifor.br
}

Artigo recebido em 16 de maio de 2016, versão final aceita em 12 de agosto de 2016.

RESUMO: Este estudo apresenta os níveis de vulnerabilidade física de segmentos costeiros à erosão, analisados para cinco praias do litoral do Ceará, a fim de representar o potencial de reação da costa aos processos atuantes no sistema praial e aos efeitos do uso e da ocupação, por meio de uma abordagem semiquantitativa. Os níveis de vulnerabilidade e os processos de erosão costeira foram estabelecidos por meio da integração de metodologias desenvolvidas por Souza (1997; 2001), Souza (1999), Dominguez (1999), Souza \& Suguio (2003) e Souza et al. (2005). Integraram-se, ainda, as características particulares de uso e de ocupação, embasadas nas metodologias de Dal Cin \& Simeoni (1994), Projeto Orla (Brasil, 2006) e Mallmann \& Araújo (2010). Estudos deste cunho constituem importantes ferramentas nos processos de gerenciamento e de gestão de zonas litorâneas, possibilitando a indicação de diretrizes para um ordenamento territorial de forma sustentável. Foi possível identificar que os fatores morfológicos costeiros, os processos litorâneos, as intervenções humanas e os atributos e dinâmica naturais influenciam fortemente a vulnerabilidade de cada praia. Os resultados obtidos demonstram que áreas que apresentam grau de vulnerabilidade muito alto coincidem com as células e setores mais urbanizados, sugerindo um controle muito mais antrópico do que natural sobre a vulnerabilidade. O índice do grau de vulnerabilidade à erosão, após a aplicação das metodologias, apresentou o mesmo resultado para cada célula delimitada. Entretanto, estas áreas necessitam de estudos específicos integrados, os quais possibilitem compreender as condições e os processos atuantes sobre o capital natural, no intuito de buscar soluções para minimizar os problemas encontrados decorrentes do mau uso e da ocupação, com a finalidade de chegar a um equilíbrio ambiental. A aplicação dos resultados registrados pode subsidiar a elaboração de planos de ordenamento territorial das praias monitoradas, tendo em vista que na maior parte delas a urbanização é acelerada e desordenada.

Palavras-chave: análise de vulnerabilidade; gerenciamento costeiro integrado; erosão costeira; praias arenosas. 
ABSTRACT: This study presents the levels of physical vulnerability of coastal erosion segments, analyzed for 5 beaches of the coast of Ceará, in order to represent the reaction potential from the coast to the processes operating in the beach system and the effects of the use and occupation through a semi-quantitative approach. The levels of vulnerability and the processes of coastal erosion were established through integration of methodologies developed by Souza (1997; 2001), Souza (1999), Dominguez (1999), Souza \& Suguio (2003), e Souza et al. (2005), also considering the particular characteristics of use and occupation, based on methodologies of Dal Cin \& Simeoni (1994), Mallmann \& Araújo (2010) and Projeto Orla (Brasil, 2006). Studies of this nature are important tools in the management processes and administration of coastal zones, allowing the indication of guidelines for a sustainable territorial development. It was possible to identify that coastal process and morphological factors, human interventions and attributes, as well as natural dynamics strongly influence the vulnerability of each beach. The results obtained show that areas which have very high vulnerability degree match the more urbanized cells and sectors, suggesting a more anthropic (man-made) than natural control over the vulnerability. The index of the vulnerability degree to erosion, after the application of the methodologies, presented the same result for each bounded cell. However, these areas require specific and integrated studies, which would allow understanding the conditions and processes acting on the natural resources, in order to seek solutions to minimize the problems arising from the improper use and occupation, aiming to reach an environmental balance. The application of the results recorded can subsidize the elaboration of spatial planning of the beaches monitored, since in most of them the urbanization is accelerated and disordered.

Keywords: vulnerability analysis; integrated coastal management; coastal erosion; sand beaches.

\section{Introdução}

A expansão urbana desordenada nas áreas costeiras é um problema conhecido em todo o mundo, com inúmeros exemplos de impactos de erosão costeira sobre cidades e balneários, além de perdas de importantes habitats de alta produtividade biológica. O crescimento populacional nessas áreas, cada vez mais próximo à linha de costa, vem desequilibrando a dinâmica costeira, ou seja, impedindo o processo natural e cíclico de retirada e reposição de sedimentos, intensificando os processos erosivos. Essa problemática foi registrada em estudos desenvolvidos por Dal Cin \& Simeoni (1994), Souza (1997; 2001), Souza (1999), Dominguez (1999), Souza \& Suguio (2003), Souza et al. (2005), Projeto Orla (Brasil, 2006), Mallmann \& Araújo (2010), Marino \& Freire (2013), Marino et al. (2012; 2013), Marino (2014), dentre outros. Zonas costeiras estão incluídas entre os ambientes mais dinâmicos existentes em nosso planeta, áreas onde é possível observar a interface continente-oceano-atmosfera e que apresentam um equilíbrio dinâmico coordenado pelas variações energéticas dos processos naturais de diferentes escalas espaciais e temporais, com grande fragilidade e vulnerabilidade frente às intervenções antrópicas (Marino \& Freire, 2013).

As praias representam sistemas transicionais, dinâmicos e sensíveis, em constante ajuste com as flutuações dos níveis de energia locais, e são produtos de um complexo sistema de forças e processos ao qual estão sujeitas. Elas atuam como uma zona tampão, protegendo a costa da ação direta da energia do oceano (Malmann \& Araújo, 2010).

Para uma melhor compreensão do contexto, Dolan et al. (1978) definem linha de costa como a "linha que representa as bordas de um corpo d'água". De acordo com Marino (2014), a posição da linha de costa é resultado de interações morfodinâmicas e controlada basicamente pelas características das ondulações geradas pelos sistemas meteorológicos e pelo balanço hídrico e sedimentar 
resultante do aporte continental e marinho, os quais influenciam diretamente no seu avanço ou recuo.

As áreas urbanas da faixa litorânea do Estado do Ceará apresentaram um maior desenvolvimento a partir da década de 70, quando da implantação das primeiras ações de desenvolvimento, tanto governamentais quanto privadas, por meio de investimentos em infraestrutura viária, de serviços e comercial. Essas ações promoveram a intensificação do fluxo migratório para as regiões costeiras e a transformação do ambiente pela exploração e pela degradação dos recursos naturais, causando impactos ambientais significativos.

Dentro deste contexto, a faixa de praia da Região Metropolitana de Fortaleza encontra-se notadamente inserida, sendo afetada por um número muito grande de fatores, alguns relacionados com as intervenções antrópicas na zona costeira (obras de engenharia, barramentos, drenagens, aterramento de praias, construção de espigões, muros de contenção, empreendimentos turístico-hoteleiros, segundas residências, etc.), outros de origem natural e relacionados à dinâmica costeira (as flutuações do nível do mar, a influência da morfologia da antepraia nas ondulações, tectonismo, transporte sedimentar costeiro, dinâmica da zona de arrebentação, erosão costeira, etc.). Entre alguns dos principais problemas ambientais agravados, destacam-se a contaminação do solo e dos mananciais hídricos, a deficiência de infraestrutura, a especulação imobiliária, o uso e a ocupação desordenada dos ecossistemas (p. ex.: praia Porto das Dunas, praia do Futuro e Beira-Mar), fatos também relatados nos levantamentos de Pinheiro (2000), Projeto Orla (Brasil, 2006), Muehe (1996a; 1996b; 2005; 2006; 2011), Albuquerque (2005), Moraes (2007), Moura (2009; 2012; 2013), Marino et al. (2012; 2013), Marino \& Freire (2013) e Marino (2014).
Nota-se que essas mudanças naturais e antrópicas, aliadas à falta de fiscalização e aplicação de leis que controlem seu uso e ocupação sem estudos prévios, provocam o desequilíbrio do ambiente praial, com a redução e/ou eliminação de algumas fontes de reposição de sedimentos que são transportados pela deriva litorânea, causando erosão costeira e degradação dos ecossistemas.

Este estudo apresenta os níveis de vulnerabilidade de segmentos costeiros à erosão, analisados para cinco praias do litoral do Ceará, a fim de representar o potencial de reação da costa aos processos atuantes no sistema praial e aos efeitos do uso e da ocupação. Análises desse cunho mostram-se de grande importância e aplicabilidade para o gerenciamento e monitoramento costeiro.

\subsection{Localização da área de estudo}

Aárea objeto deste estudo encontra-se inserida na zona costeira leste da Região Metropolitana de Fortaleza, localizada na carta topográfica Aquiraz (SA 24-Z-C-V), Estado do Ceará, Brasil (Brasil, 1971). A área foi dividida em três setores, levando-se em consideração a localização das desembocaduras do rio Pacoti e do rio Cocó, onde se tem: Setor 1 - representado em vermelho pela célula costeira da Praia Porto das Dunas (Ponto 1) até a margem direita do rio Pacoti; Setor 2 - na cor verde, abrange a Praia da Abreulândia - COFECO (Ponto 2) e a Praia da Sabiaguaba (Ponto 3), situadas entre as desembocaduras dos rios Pacoti e Cocó; e Setor 3 - cor laranja, constituído pela Praia do Caça e Pesca (Ponto 4) e pela Praia do Futuro - Barraca Vira Verão (Ponto 5), conforme a Figura 1. 


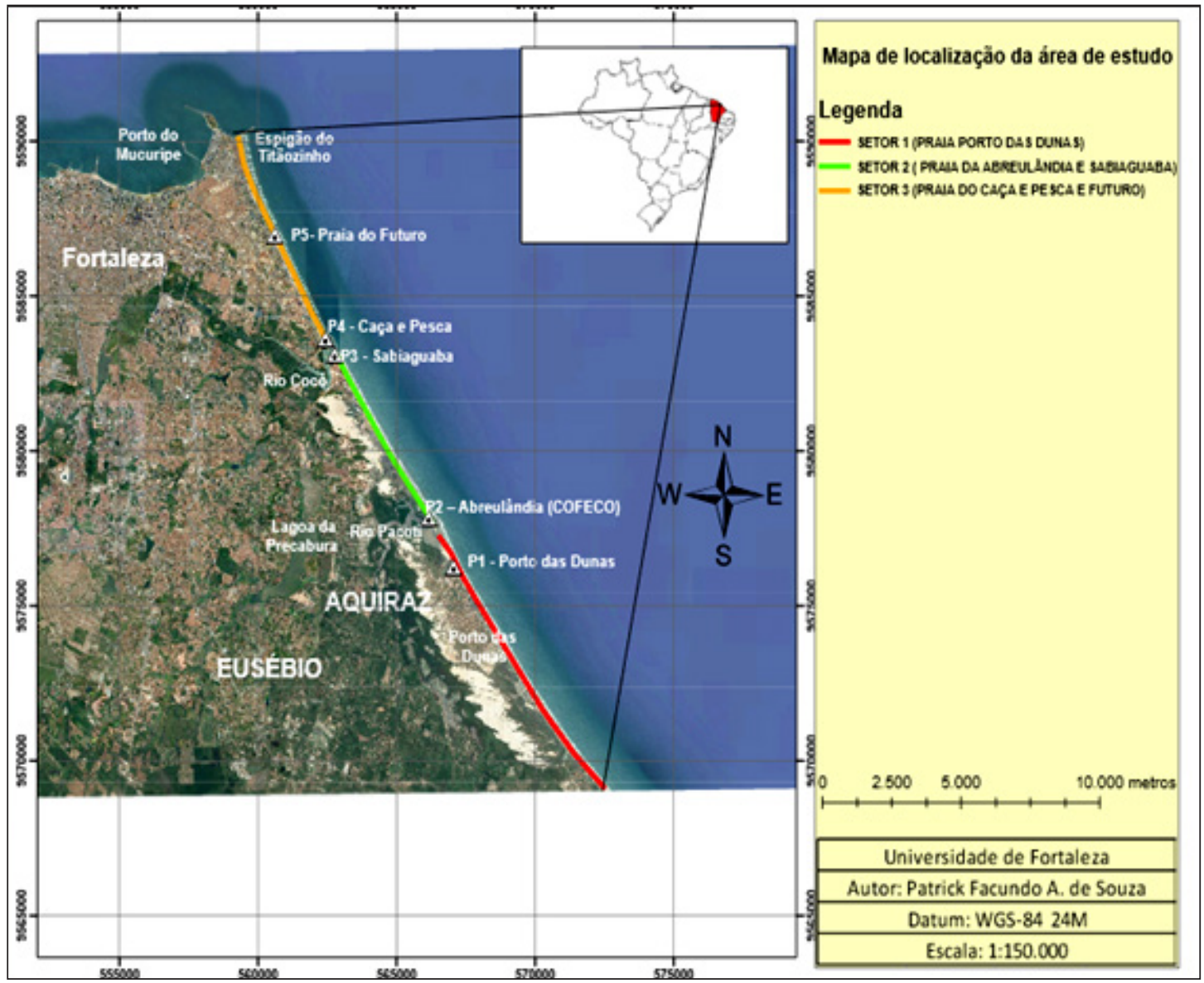

FIGURA 1 - Localização da área de estudo.

FONTE: Google Earth (2010).

\section{Erosão costeira: indicadores, métodos e vulnerabilidade}

Vários trabalhos abordam os processos de recuo e avanço do mar na zona litorânea brasileira e no mundo, ressaltando-se os estudos de: Dias (1990), Morais (1996), Bird (1996), Maia et al. (1997); Pinheiro (2000), Muehe (1996a; 1996b; 2001; 2005; 2011), Martins et al. (2004), Moura et al. (2007), Sousa (2007), Marino \& Freire (2013),
Marino et al. (2012, 2013), Marino (2014), dentre outros.

A erosão costeira é registrada nos trabalhos de Souza et al. (2005) como um processo decorrente da redução do balanço sedimentar que, por vezes, diminui a largura da praia e, consequentemente, provoca a perda e os desequilíbrios dos habitat naturais. Esse processo pode maximizar as inundações decorrentes de ressacas, provocando a destruição de infraestruturas antrópicas e a perda do valor cênico e turístico dessas áreas. 
Cerca de $20 \%$ das linhas de costa do planeta são formadas por praias arenosas, nas quais Bird $(1985 ; 1996)$ registrou a ocorrência do processo de erosão em $70 \%$ e progradação em $20 \%$, com apenas $10 \%$ dessas praias em equilíbrio relativo.

Alguns estudos sobre os processos erosivos nas praias brasileiras apontam os fenômenos naturais e/ou antrópicos como condicionantes do processo de erosão costeira, sendo difícil identificar ou mesmo fragmentar o fator preponderante, de acordo com a Tabela 1 (Souza et al., 2005). As intervenções antrópicas, seguidas da ocupação da orla, são as causas primordiais do processo erosivo apontadas por Muehe (2001).
Nas últimas décadas, vários pesquisadores vêm discutindo as causas da erosão costeira e apontam a elevação do nível do mar e o balanço sedimentar negativo como os principais agentes responsáveis pelo fenômeno, dentre os quais podemos citar: Bruun, (1962), Bird (1985), Souza \& Suguio (2003), Dillenburg et al. (2004), Dominguez (2007), dentre outros.

Souza, C. (1997; 2001), Souza, M. (1999), Dominguez (1999) e Souza \& Suguio (2003) desenvolveram uma metodologia para se classificar uma praia quanto às causas antrópicas e naturais (Tabela 2).

TABELA 1 - Indicadores de erosão costeira apresentados por Souza et al. (2005, p. 139).

\section{Indicadores de erosão costeira}

I - Pós-praia muito estreita ou inexistente devido à inundação permanente durante as preamares de sizígia (praias urbanizadas ou não).

II - Retrogradação geral da linha de costa nas últimas décadas, com diminuição da largura da praia em toda a sua extensão, ou mais acentuadamente em determinados locais (praias urbanizadas ou não).

III - Erosão progressiva de depósitos marinhos e/ou eólicos pleistocênicos a atuais que bordejam as praias, sem o desenvolvimento de falésias ou escarpamentos em dunas e terraços marinhos (praias urbanizadas ou não).

IV - Presença de falésias com alturas de até dezenas de metros em rochas sedimentares mesozoicas, sedimentos terciários (Formação Barreiras) e rochas de praia pleistocênicas e holocênicas, e presenças de escarpamentos em depósitos marinhos e/ou eólicos pleistocênicos a atuais que bordejam as praias (praias urbanizadas ou não).

$\mathbf{V}$ - Destruição de faixas frontais de vegetação de "restinga" ou de manguezal e/ou presença de raízes e troncos em posição de vida soterrados na praia, devido à erosão e soterramento causados pela Retrogradação/migração da linha de costa, ou por processos de sobrelavagem (ilhas e praias-barreiras).

VI - Exumação e erosão de depósitos paleolagunares, turfeiras, arenitos de praia ou terraços marinhos holocênicos e pleistocênicos, sobre o estirâncio e/ou a face litorânea atuais, devido à remoção das areias praiais por erosão costeira e déficit sedimentar extremamente negativo (praias urbanizadas ou não).

VII - Frequente exposição de "terraços ou falésias artificiais!", apresentando pacotes de espessura até métrica, formados por sucessivas camadas de aterros soterrados por lentes de areias praias/dunares (contato entre a praia e a área urbanizada).

VIII - Construção e destruição de estruturas artificiais erguidas sobre os depósitos marinhos ou eólicos holocênicos que bordejam a praia, a pós-praia, o estirâncio, a face litorânea e/ou zona de surfe.

IX - Retomada erosiva de antigas plataformas de abrasão marinha, elevadas de $+2 \mathrm{a}+6 \mathrm{~m}$, formadas sobre rochas do embasamento ígneo-metamórfico pré-cambriano a mesozoico, ou rochas sedimentares mesozoicas, ou sedimentos terciários (Formação Barreiras) ou arenitos praiais pleistocênicos, em épocas em que o nível do mar encontrava-se acima do atual, durante o final do Pleistoceno e o Holoceno (praias urbanizadas ou não).

$\mathbf{X}$ - Presença de concentrações de minerais pesados em determinados trechos da praia, em associação com outras evidências erosivas (praias urbanizadas ou não).

XI - Presença de embaiamentos formados pela atuação de correntes de retorno concentradas associadas a zonas de barlamar ou centros de divergência de células de deriva litorânea localizados em local mais ou menos fixo da praia, podendo ocorrer também processos de sobrelavagem (ilhas e praias-barreiras). 
TABELA 2 - Causas naturais e antrópicas da erosão costeira e efeitos e processos associados apresentados por Souza et al. (2005, p. 140, 141 e 142).

1. Dinâmica de circulação costeira: Na zona de barlamar de uma célula de deriva litorânea, o processo erosivo é naturalmente predominante. presença de centros de divergência Em um centro de divergência de duas células, o processo erosivo é mais intenso, podendo ocorrer fortes de células de deriva litorânea em correntes de retorno e embaiamentos na praia. A ocorrência dessas células em locais mais ou menos fixos determinados locais mais ou menos da praia foi destacada por Souza (1997) em São Paulo e por Calliari et al. (1998) na costa do Rio Grande fixos da linha de costa e atuação do Sul, onde o fenômeno gerado pela concentração de energia de ondas por processos de refração em certos efeito "foco estável". trechos da linha de costa foi denominado "foco estável".

2. Morfodinâmica praial: mobilidade e Praias intermediárias têm maior mobilidade e variabilidade temporal devidoà presença de correntes de suscetibilidade à erosão costeira. retorno e barras submersas extremamente móveis, sendo, portanto, as mais susceptíveis à erosão. As reflexivas de alta energia (expostas) são mais susceptíveis à erosão do que as dissipativas de alta energia (estas apresentam alto estoque sedimentar no perfil submerso). Os locais de maior erosão são associados aos embaiamentos em praias intermediárias e dissipativas de alta energia. As dissipativas e reflexivas de baixa energia (abrigadas) são as mais estáveis e menos susceptíveis à erosão, exibindo baixa variabilidade temporal e espacial.

3. Aporte sedimentar atual natural- $\mathrm{O}$ aporte sedimentar constante equilibra o balanço de sedimentos na linha de costa, principalmente em mente ineficiente (continente, praia situações de elevação do nível do mar. Se esse suprimento é ineficiente, haverá erosão costeira, seja pela e fundo marinho adjacente). ausência de grandes rios, pela eficiência de perdas ao longo da costa, ou pela retenção de sedimentos na plataforma continental e/ou campo de dunas adjacentes às praias.

4. Presença de irregularidades na li- Quando essas irregularidades da linha de costa estão presentes, ocorre forte dispersão de sedimentos e nha de costa: mudanças bruscas na erosão em certos trechos. Eles causam a interrupção local da deriva litorânea resultante, provocando: acuorientação da linha de costa, pro- mulação de sedimentos à montante dessas irregularidades e erosão à jusante, pois duas pequenas células montórios rochosos e cabos incon- de deriva litorânea de mesmo sentido são geradas; e/ou a dispersão de sedimentos rumo ao oceano devido solidados. à atuação de correntes de retorno.

5. Presença de amplas zonas de trans- Em certos segmentos longos e retos da linha de costa, a zona de transporte da célula de deriva litorânea porte ou trânsito de sedimentos (by-pass). resultante é muito ampla, causando simultaneamente erosão e deposição de sedimentos, que pouco permanecem na praia, pois estão em trânsito contínuo. O resultado é, em geral, a erosão praial, principalmente quando outros fatores contribuem para um déficit sedimentar.

6. Elevações do NM de curto período Esses fenômenos referem-se a variações horárias, diárias e sazonais definidas por Mesquita (2000). Ocorre devido a efeitos combinados de fe- a inundação de praias, dunas e parte das planícies costeiras e a migração de todo o perfil praial rumo ao nômenos astronômicos, meteoroló- continente, causando erosão severa na linha de costa e destruição de estruturas construídas pelo homem. gicos e oceanográficos.

7. Modificação da deriva litorânea de- A migração de desembocaduras causada por correntes de deriva litorânea mais intensa do que o fluxo fluvido à presença de desembocaduras vial tem efeito erosivo direto sobre a linha de costa no sentido da migração. Quando o fluxo fluvial é mais fluviais (migração lateral e efeito intenso do que a deriva litorânea, ocorre o efeito "molhe hidráulico", havendo forte acúmulo de sedimentos "molhe hidráulico"), obstáculos si- a barlamar da deriva litorânea e erosão intensa a sotamar (duas pequenas células são formadas). Os obstátuados na zona próxima à praia (bar- culos costa-afora promovem fenômenos de difração e refração das ondas, induzindo à geração de pequenas ras de desembocadura fluvial, ilhas, células de deriva litorânea que convergem para uma zona de sombra atrás do obstáculo, que constituem parcéis, arenitos de praia e recifes), excelentes armadilhas de sedimentos (tômbolos). Baías abertas no sentido da deriva litorânea e desembobaías e desembocaduras lagunares. caduras lagunares são também armadilhas de naturais de sedimentos, provocando déficit sedimentar nas praias a sotamar das células de transporte costeiro.

8. Inversões bruscas de orientação na Eventos de "El Niño" alteram o regime de ventos e de ondas, podendo causar inversão das correntes de deriva litorânea causadas por fenô- deriva litorânea. Isto tem sido observado principalmente nas planícies costeiras e praias das costas leste menos climático-meteorológicos, e nordeste do Brasil (situação normal: de sul para norte; situação de "El Niño": de norte para sul) e concom a passagem de ciclones extra- sequente erosão praial. Nas costas sul e sudeste, o "El Niño" parece não afetar a circulação costeira tão tropicais ou Anticiclone Tropical intensamente, a qual é mais sensível às passagens de sistemas frontais estacionários (ventos e ondas proAtlântico (frentes frias estacioná- venientes de SSW/S-SSE), que podem gerar inversões no sentido da deriva litorânea resultante em certos rias) e a atuação intensa do "El Niño/ trechos da linha de costa mais aberta.

ENOS (El Niño-Oscilação Sul)".

9. Efeitos primários da elevação do O predomínio de erosão costeira é um dos principais efeitos de elevação do NM, provocando a retrograNM durante o último século, em ta- dação da linha de costa e a diminuição geral da largura das praias. Estruturas construídas pelo homem são xas de até $50 \mathrm{~cm} /$ século ou $4 \mathrm{~mm} /$ constantemente destruídas. ano. 
10. Estudos secundários da elevação de Estudos sobre as modificações no comportamento da batimetria da plataforma continental paulista, entre NM de longo período - Regra de as isóbatas de 0 a 50m, mostram um deslocamento generalizado das isóbatas rumo ao oceano e a diminuiBruun: processos erosivos no perfil ção da declividade da plataforma continental no período de 1938 a 1994, sugerindo que parte das areias emerso da praia e deposição no per- esteja sendo erodida da praia subaérea e transportada e retida no fundo marinho adjacente (zona próxima fil submerso e fundo marinho adja- à praia e zona de transição). cente (perfil de equilíbrio).

11. Evolução quaternária das planícies A maior ou menor presença de sedimentos quaternários reflete se o balanço sedimentar foi negativo ou costeiras: balanço sedimentar de positivo e também o comportamento geral do transporte costeiro. Áreas que estiveram sujeitas a intensa longo prazo negativo e dinâmica e erosão no passado ou a grande retenção de sedimentos por processos eólicos (grandes campos de dunas) circulação costeira atuante na épo- têm atualmente baixo estoque de sedimentos disponível no sistema costeiro. ca.

12. Balanço sedimentar atual negativo $\mathrm{O}$ déficit de sedimentos em uma praia pode ser causa e efeito dos processos erosivos. Todos os fatores originado por processos naturais in- naturais citados acima também induzem ao balanço sedimentar negativo nas praias. dividuais ou combinados.

\section{Retirada de areia de praias e dunas. Causa erosão na praia local e em áreas vizinhas, alterando o balanço sedimentar das mesmas.}

14. Fatores tectônicos.

Embora esses fatores não sejam ainda bem conhecidos na costa do Brasil, estudos realizados no Rio Grande do Norte sugerem que a neotectônica tem exercido papel fundamental na atuação de processos erosivos costeiros de longo período, condicionando em altos e baixos estruturais (horstes e grabens) a formação de falésias de até $15 \mathrm{~m}$ de altura (áreas de localização dos horstes) e de baías em forma de zeta (grabens). Estas feições morfológicas, por sua vez, têm sido esculpidas pela erosão diferencial de sedimentos da Formação Barreiras associada a padrões de refração e difração de ondas de direção persistente (Diniz, 1998; Vital et al., no prelo).

15. Urbanização da orla, com destruição Essas intervenções causam processos erosivos diretos, por eliminarem um dos estoques sedimentares da de dunas e/ou impermeabilização praia e interferem na articulação de correntes costeiras, principalmente durante as ressacas e preamares de de terraços marinhos holocênicos e sizígia em algumas praias.

eventual ocupação do pós-praia.

16. Implantação de estruturas rígidas ou Espigões (de pedra ou bolsa-roca), molhes, enrocamentos, guias-corrente, canais de drenagem, anteparos flexíveis, paralelas ou transversais à e muros/muretas (pedra, concreto e outros materiais), gabiões e quebra-mares interferem na circulação de linha de costa (em geral para conter correntes costeiras, pois modificam o ângulo de incidência das ondas, alteram o perfil praial e o regime ou mitigar a erosão costeira). sedimentar. Em geral, elas intensificam os problemas erosivos. Recifes artificiais implantados na plataforma continental interna rasa também podem modificar o clima de ondas, o padrão de refração das ondas incidentes e estacionárias, causando modificações no perfil praial.

17. Armadilhas de sedimentos associa- As estruturas artificiais não paralelas à linha de costa são efetivas armadilhas de sedimentos, pois interdas à implantação de estruturas arti- rompem as correntes de deriva litorânea, dividindo a célula original em duas células de deriva litorânea ficiais. menores. Haverá acumulação de sedimentos à barlamar da estrutura (que na verdade passa a ser a zona de sotamar de uma das células) e erosão intensa à sotamar da estrutura (que passa a ser zona de barlamar da outra nova célula).

18. Extração de areias fluviais (desas- Alteram o balanço sedimentar regional e desencadeiam processos erosivos nos sistemas fluvial, estuarino soreamento de desembocaduras e e lagunar e nas praias. Por outro lado, podem aumentar o aporte de sedimentos no sistema costeiro, pelo mineração) e dragagens em canais menos momentaneamente. de maré na plataforma continental.

19. Conversão de manguezais, planí- Essas modificações causam desequilíbrios no balanço sedimentar regional, aumentando os processos erocies fluviais e lagunares, pântanos sivos no sistema costeiro e, consequentemente, nas praias. Além disso, muitos desses terrenos passam a e áreas inundadas em terrenos para ser susceptíveis a inundações. urbanização e atividades antrópicas; mudanças no padrão de drenagem.

20. Balanço sedimentar atual negativo O déficit de sedimentos em uma praia pode ser causa e efeito dos erosivos. Todos os fatores antrópicos decorrente de intervenções antrópi- citados acima também induzem ao balanço sedimentar negativo nas praias. cas.

* NM - nível do mar 
Desde a década de 1970, vários autores estudam o litoral do Ceará em relação aos impactos negativos resultantes da erosão costeira, como Morais (1996) e Albuquerque (2008) no município de Fortaleza, Pinheiro (2000), Moura et al. (2007) no município de Caucaia, Moura (2009; 2012; 2013), Marino \& Feire (2013), Marino et al. (2013) e Marino (2014) nos municípios de Aquiraz, Fortaleza e Caucaia, dentre outros.

\subsection{Métodos para a caracterização dos processos erosivos}

Mallmann (2008) e Souza et al. (2005) propuseram alguns métodos, diretos e indiretos, para diagnóstico e quantificação dos processos erosivos (Tabela 3 ).
Souza, C. (1997; 2001), Souza, M. (1999), Dominguez (1999) e Souza \& Suguio (2003) elaboraram uma matriz de classificação de risco à erosão costeira para as praias do litoral brasileiro (Tabela 4), utilizando os métodos e embasados na identificação dos indicadores de erosão costeira (Souza et al., 2005).

As modificações na posição da linha de costa decorrem em grande parte pela falta de sedimentos, provocada pelo esgotamento da fonte, principalmente da plataforma continental. O processo se dá pela transferência de sedimentos para os campos de dunas ou por efeitos decorrentes de intervenção do homem, principalmente construção de barragens ou obras que provocam a retenção do fluxo de sedimentos ao longo da costa (Muehe, 2006).

TABELA 3 - Métodos para diagnóstico e quantificação da erosão costeira, segundo Mallmann (2008).

\begin{tabular}{|c|c|c|c|c|}
\hline Método & Tipo & Princípios & Vantagens & Desvantagens \\
\hline $\begin{array}{l}\text { Mapas } \\
\text { Históricos }\end{array}$ & Indireto & $\begin{array}{l}\text { Cálculo das distâncias en- } \\
\text { tre duas ou mais linhas de } \\
\text { costa multitemporais. }\end{array}$ & $\begin{array}{l}\text { Permite resgatar linhas de } \\
\text { costa antigas e trabalhar em } \\
\text { larga escala espacial; apre- } \\
\text { senta custo relativamente } \\
\text { baixo. }\end{array}$ & $\begin{array}{l}\text { Apresenta erros decorrentes da imprecisão da li- } \\
\text { nha de costa, da distorção dos mapas originais e } \\
\text { das diferenças de datum; não permite avaliação } \\
\text { de mudanças de curto-tempo. }\end{array}$ \\
\hline GPS & Indireto & $\begin{array}{l}\text { Uso do GPS ou DGPS } \\
\text { deslocando-se sobre a fei- } \\
\text { ção indicadora a bordo de } \\
\text { um veículo ou transporta- } \\
\text { do por operador. }\end{array}$ & $\begin{array}{l}\text { Constitui um método rápido } \\
\text { e preciso; permite cobertura } \\
\text { de longos segmentos de cos- } \\
\text { ta; apresenta custo relativa- } \\
\text { mente baixo. }\end{array}$ & $\begin{array}{l}\text { Não permite o resgate de linhas de costa preté- } \\
\text { ritas. }\end{array}$ \\
\hline $\begin{array}{l}\text { Imagens de } \\
\text { Satélite }\end{array}$ & Indireto & $\begin{array}{l}\text { Identificação da linha de } \\
\text { costa e cálculo das distân- } \\
\text { cias entre linhas de costas } \\
\text { de diferentes épocas sobre } \\
\text { imagem registrada. }\end{array}$ & $\begin{array}{l}\text { Permite o estudo relativa- } \\
\text { mente rápido de extensas } \\
\text { áreas. }\end{array}$ & $\begin{array}{l}\text { Imagens de baixa resolução apresentam dificul- } \\
\text { dade de delimitar a linha de costa; imagens de } \\
\text { alta resolução apresentam custo elevado. }\end{array}$ \\
\hline $\begin{array}{l}\text { Perfis } \\
\text { topográficos }\end{array}$ & Direto & $\begin{array}{l}\text { Obtenção de dados de alti- } \\
\text { tude e distância }\end{array}$ & $\begin{array}{l}\text { Trata-se de um método } \\
\text { simples e de baixo custo; } \\
\text { permite diagnosticar mu- } \\
\text { danças de curto-tempo, } \\
\text { bem como um estudo tridi- } \\
\text { mensional. }\end{array}$ & $\begin{array}{l}\text { Pontual, inviabiliza o estudo de áreas extensas; } \\
\text { não permite resgatar informações pretéritas. }\end{array}$ \\
\hline
\end{tabular}


TABELA 4 - Matriz de classificação de risco à erosão costeira, segundo Souza et al. (2005, p. 145).

\begin{tabular}{|c|c|c|c|c|}
\hline \multirow{2}{*}{$\begin{array}{c}\text { Número } \\
\text { total de } \\
\text { indicadores } \\
\text { de erosão } \\
\text { costeira }\end{array}$} & \multicolumn{4}{|c|}{ Distribuição espacial na praia } \\
\hline & $>60 \%$ & $41-60 \%$ & $21-40 \%$ & $<20 \%$ \\
\hline 10 a 11 & Muito Alto & Muito Alto & Alto & Alto \\
\hline 7 a 9 & Muito Alto & Alto & Médio & Médio \\
\hline 4 a 6 & Alto & Médio & Médio & Baixo \\
\hline 1 a 3 & Médio & Médio & Baixo & Baixo \\
\hline 0 & \multicolumn{4}{|c|}{ Muito Baixo } \\
\hline
\end{tabular}

A linha de costa é um elemento geomorfológico que apresenta alta dinâmica espacial decorrente de respostas a processos costeiros de diferentes magnitudes e frequências. Suas mudanças de posição são de natureza complexa, envolvendo diversos processos ligados às variações do nível do mar (em curto e longo prazo), balanço de sedimentos, movimentos tectônicos e reológicos, e antrópicos (Camfield \& Morang, 1996).

As praias arenosas são utilizadas pelo homem para diversos fins, destacando aqueles de natureza recreacional e turística. A crescente demanda por tais usos nos municípios litorâneos induz muitas vezes a um desenvolvimento sem planejamento, desconsiderando a natureza móvel e dinâmica da linha de costa.

O mapeamento sistemático dessa linha e o acompanhamento de suas mudanças representam ferramentas para a geração de informações de grande valor para o planejamento e o gerenciamento costeiros, pois fornecem subsídios para o estabelecimento de faixas de recuos (setback) da zona litorânea, permitem a determinação de áreas de risco de erosão costeira e contribuem também com informações para a implantação de obras de intervenção direta na linha de costa (guias correntes, molhes, engordamento de praia, etc.) (Anders \& Byrnes, 1991; Crowell et al., 1991).
Estudos envolvendo a determinação das taxas de recuo de linha de costa vêm sendo realizados desde a segunda metade do século passado, utilizando para tal os mais diversos métodos de comparação cartográfica, medições diretas em fotografia aérea vertical, medições periódicas no terreno, técnicas fotogramétricas, utilização de imagens de satélite, etc., visando como resultado final, considerando a degradação da zona costeira, à obtenção de previsões dinâmicas do comportamento da linha de costa (Short \& Trembanis, 2004; Calhaghan et al., 2009).

\subsection{Vulnerabilidade da praia à erosão costeira}

Dentro do cenário mundial, vários pesquisadores têm discutido sobre vulnerabilidade, riscos, impactos e ações mitigadoras no ambiente costeiro, dentre os quais Harvey et al. (1999), Bush et al. (1999), Pinheiro (2000), Tagliani (2003) e Lins-de-Barros (2005) podem ser destacados.

O risco nas zonas litorâneas, de acordo com Lins-de-Barros (2005), pode estar associado, na maioria das vezes, ao perigo das correntes e das ondas, entretanto, não se pode negligenciar as interferências do homem, que podem vir a aumentar ou reduzir esses riscos. Dentro desse contexto, a autora considera que o risco está sempre associado à probabilidade de determinado perigo gerar prejuízos à sociedade, sejam estes materiais ou para a saúde e a vida humana.

O termo vulnerabilidade encerra grande número de variáveis que transcorrem pelas áreas sociais, ambientais, econômicas e culturais, dentre outros. Nesse sentido, o conceito de vulnerabilidade física aplicada neste estudo é "o estado de fragilidade natural de determinada costa a eventos erosivos em curta ou longa escala temporal" (Lins-de-Barros, 2005). 
Moura (2012) aborda o grau de vulnerabilidade de um ambiente litorâneo ou, mais especificamente, de uma praia, a partir dos deslocamentos da linha de costa, suas características e seu estado de equilíbrio, analisando o comportamento com que um processo ou um componente do sistema sofre ataques do agente impactante.

Mallmann \& Araújo (2010) apresentaram uma proposta metodológica para estimar a vulnerabilidade de segmentos costeiros à erosão por meio de uma abordagem semiquantitativa, ferramenta importante no processo de gerenciamento costeiro, tendo em vista que possibilita o estabelecimento de áreas prioritárias para a gestão (Tabela 5).
A metodologia de Mallmann \& Araújo (2010) foi embasada nos estudos referentes ao tema (Dal Cin \& Simeoni, 1994; Esteves \& Finkl, 1998; Thieler \& Hammar-Klose, 1999; Souza \& Suguio, 2003) e associada à compilação de dados secundários e à sistematização dos dados coletados em campo. Os dados qualitativos e quantitativos são codificados em pesos proporcionais à sua influência sobre um Î́ndice de Vulnerabilidade Global (IVG), que, por sua vez, é calculado a partir de cinco Índices Parciais de Vulnerabilidade (IPVs), relacionados: à morfologia costeira, à presença de atributos naturais, à influência marinha, aos processos costeiros e a fatores antrópicos.

TABELA 5 - Variáveis utilizadas para o cálculo dos índices de vulnerabilidade e seus pesos correspondentes, apresentadas por Mallmann \& Araújo (2010).

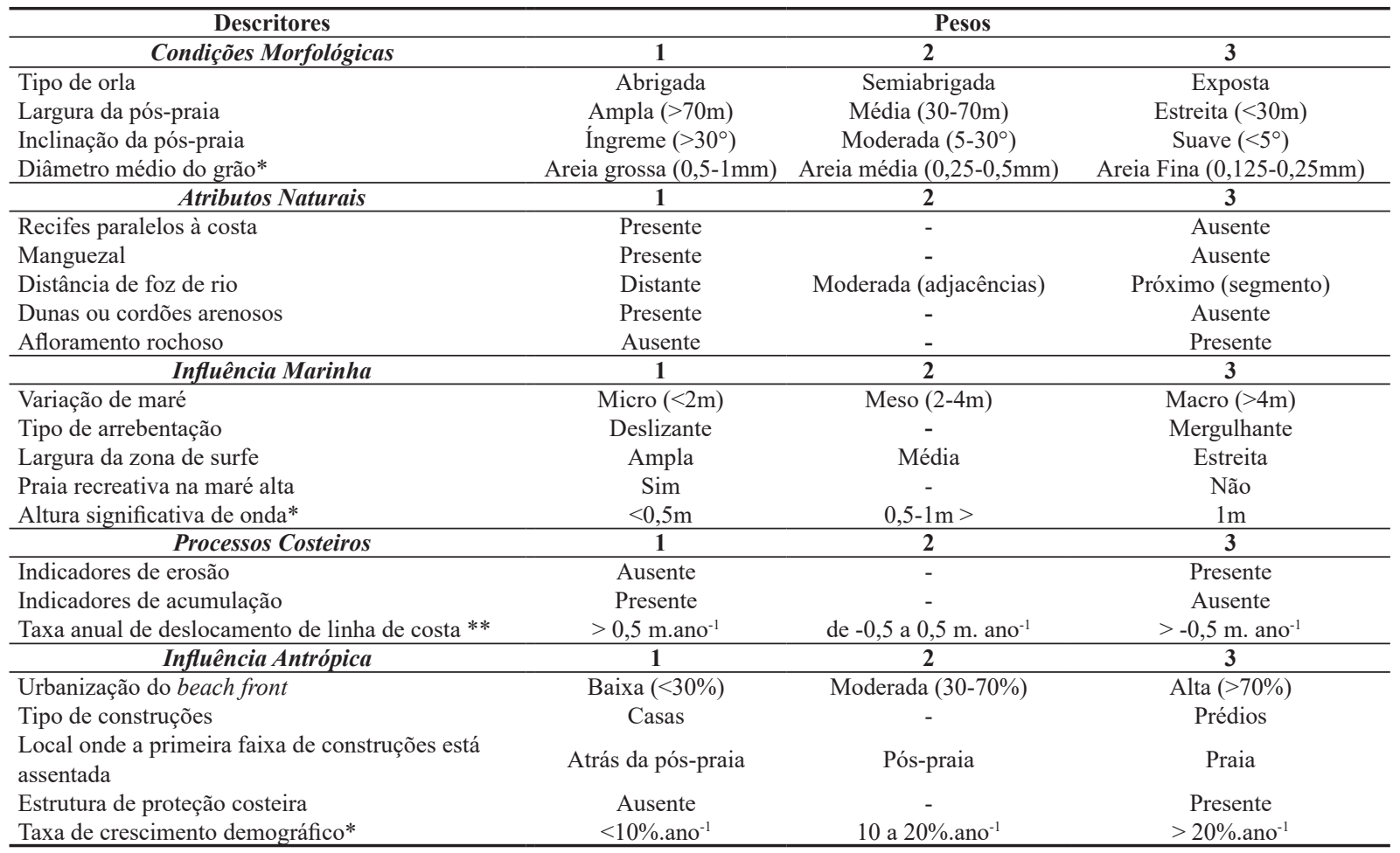

* Dados obtidos ou calculados a partir de informações preexistentes.

** Dados obtidos a partir de fotografias aéreas e caminhamentos com GPS (intervalo de 1961-2006).

Demais dados: obtidos por medições e observações em campo. 
De acordo com o Projeto Orla (Brasil, 2006, p. 31, 32 e 33), é possível analisar o tipo de orla, classificado em:

Orla abrigada é um ambiente litorâneo constituído por golfos, baías, enseadas, estuários ou praias protegidas da incidência direta de ondas, com taxa de circulação restrita e, consequentemente, baixa taxa de renovação da água. Este tipo de orla raramente apresenta sistemas de dunas frontais desenvolvidas. Frequentemente exibe amplas planícies com presença de costões e/ou ecossistemas inundáveis do tipo marismas, manguezais, campos de gramíneas submersas, planícies lamosas, etc. Geralmente apresenta sedimentos de granulometria fina (areia fina e muito fina, silte e argila) e salinidade sujeita a flutuações acentuadas em função de sua maior interação com os sistemas continentais e da baixa dinâmica de origem marinha. Denota-se a presença de praias com formato predominantemente côncavo, típicas de litorais recortados e com face pouco ou não voltada para a direção de maior incidência da ação dominante dos ventos e ondas.

Orla exposta é constituída por costões rochosos ou praias oceânicas, com elevada taxa de circulação e renovação de água, geralmente caracterizada por praias abertas, com zona de arrebentação bem desenvolvida e presença frequente de sistemas de dunas frontais (que podem variar quanto ao nível de desenvolvimento e quanto à presença de vegetação fixadora). As praias apresentam formato de baixa concavidade, sendo mais retilíneas e de orientação normal à direção de maior incidência da ação dominante dos ventos e ondas, com sedimentos geralmente compostos por areia grossa, média e fina.

Orla semiexposta apresenta características intermediárias entre as áreas expostas e abrigadas. O sistema tem similaridade com o de praias protegidas, porém o tamanho ou orientação da praia permite alguma ação hidrodinâmica periódica relacionada com fenômenos meteorológicos e/ou oceanográficos. Frequentemente ocorrem, nesse tipo, praias abertas para a entrada de baías ou de enseadas muito amplas, protegidas da ação direta dos sistemas frontais predominantes, apresentando comumente formato côncavo ou de baixa concavidade, com a presença de granulome- tria constituída por areia média a muito fina. Podem ocorrer trechos mais sujeitos à ação de ondas e praias mais protegidas em função de processos de refração e difração.

Dal Cin \& Simeoni (1994) associaram o grau de urbanização e as intervenções antrópicas presentes na faixa litorânea para caracterizar a vulnerabilidade costeira. Essa metodologia ainda pode retratar uma análise do risco presente em cada faixa. Os autores caracterizam três graus de vulnerabilidade de praia: a) Baixo - associado a uma praia que possui pós-praia e estirâncio bem desenvolvidos e ausência de obras de contenção; b) Médio - praia que apresenta uma frágil estabilidade, com obras de fixação no setor de pós-praia; e c) Alto - praia com ausência de pós-praia, um reduzido estirâncio e com forte presença de estruturas de proteção.

Apesar das inúmeras metodologias desenvolvidas e aplicadas na determinação do grau de vulnerabilidade costeira à erosão, não existe um padrão, algumas ainda estão em fase de teste e necessitam de uma validação científica pelos pares.

Moraes (2007) elaborou uma proposta de classificação para a tipologia dos espaços praiais por nível de ocupação, parte integrante do Projeto Orla (Brasil, 2006). O autor busca visualizar a área na sua forma de ocupação, a ocupação sugerida nos critérios do projeto e a geração de um modelo de ocupação futura. Esta classificação apresenta 13 tipos de praia, agrupadas em quatro classes: praia urbana, praia suburbana, praia rural e praia plano, caracterizadas na Tabela 6 .

Diante desse cenário, os estudos e as metodologias desenvolvidas podem ser aplicados para subsidiar o gerenciamento costeiro no que diz respeito ao monitoramento ambiental e ao ordenamento territorial, buscando-se sempre o desenvolvimento sustentável das áreas costeiras. 
TABELA 6 - Classificação das praias por níveis de ocupação, segundo Moraes (2007).

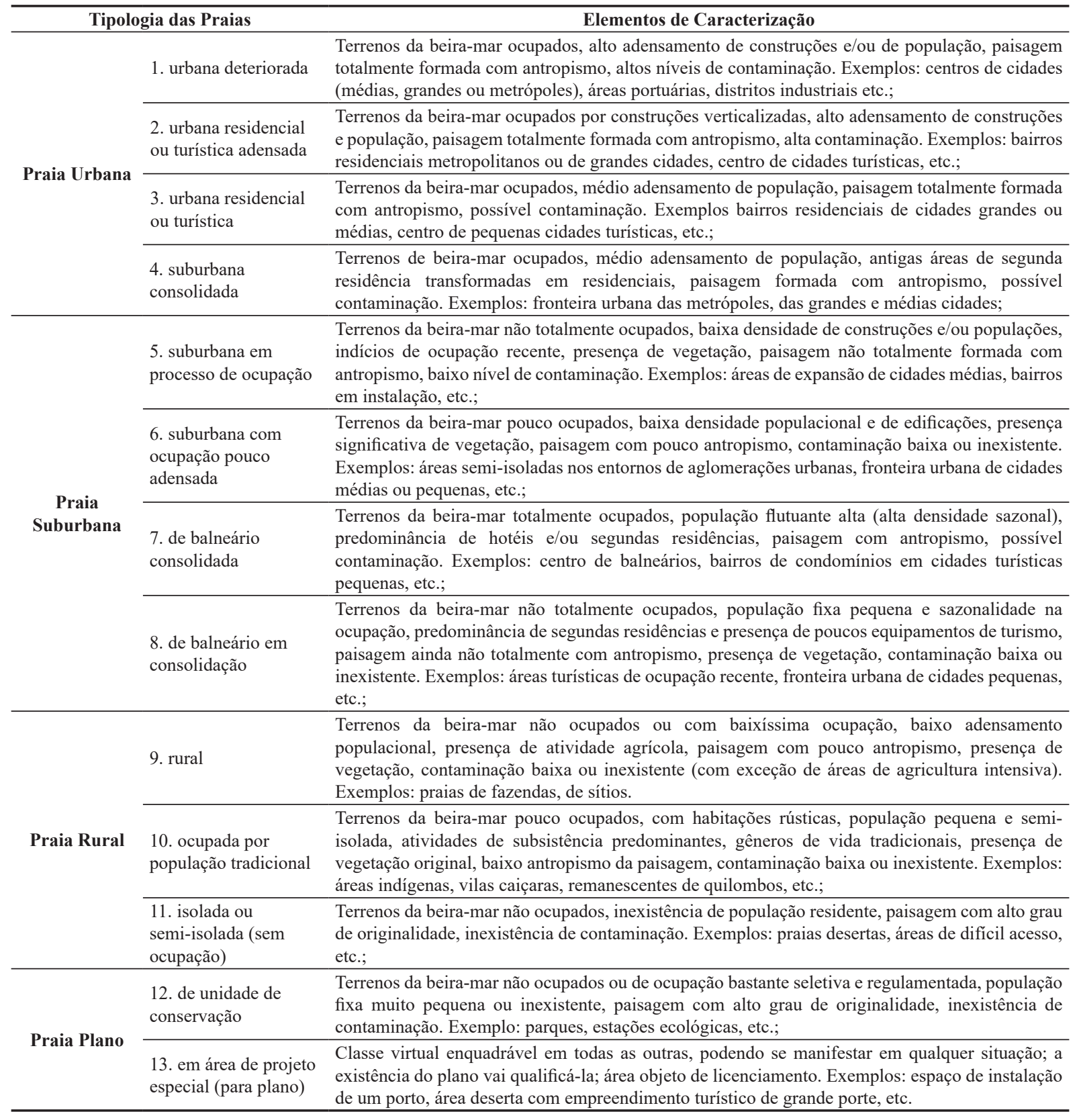




\section{Metodologia}

Os procedimentos metodológicos adotados visaram a um melhor entendimento da vulnerabilidade física à erosão atuante em parte do litoral leste da Região Metropolitana de Fortaleza, consistindo desde o levantamento de dados e informações, em campo e em laboratório, à integração das informações (Figura 2), até a confecção de produtos cartográficos representativos das feições morfológicas, da sedimentologia, do transporte sedimentar eólico, da análise multitemporal de médio e curto períodos da linha de costa e, por último, a integração de todos estes fatores para o cálculo do índice de vulnerabilidade física à erosão das cinco praias estudadas.

Os níveis de vulnerabilidade e os processos de erosão costeira das praias monitoradas foram estabelecidos por meio da integração de estudos e análises desenvolvidos, aplicando-se a metodologia proposta por Souza, C. (1997; 2001); Souza, M. (1999); Dominguez (1999); Souza \& Suguio (2003) e Souza et al. (2005). Integraram-se, ainda, as características particulares e de ocupação, tomando-se como base as metodologias propostas por Dal Cin e Simeoni (1994), Projeto Orla (Brasil, 2006) e Mallmann \& Araújo (2010).

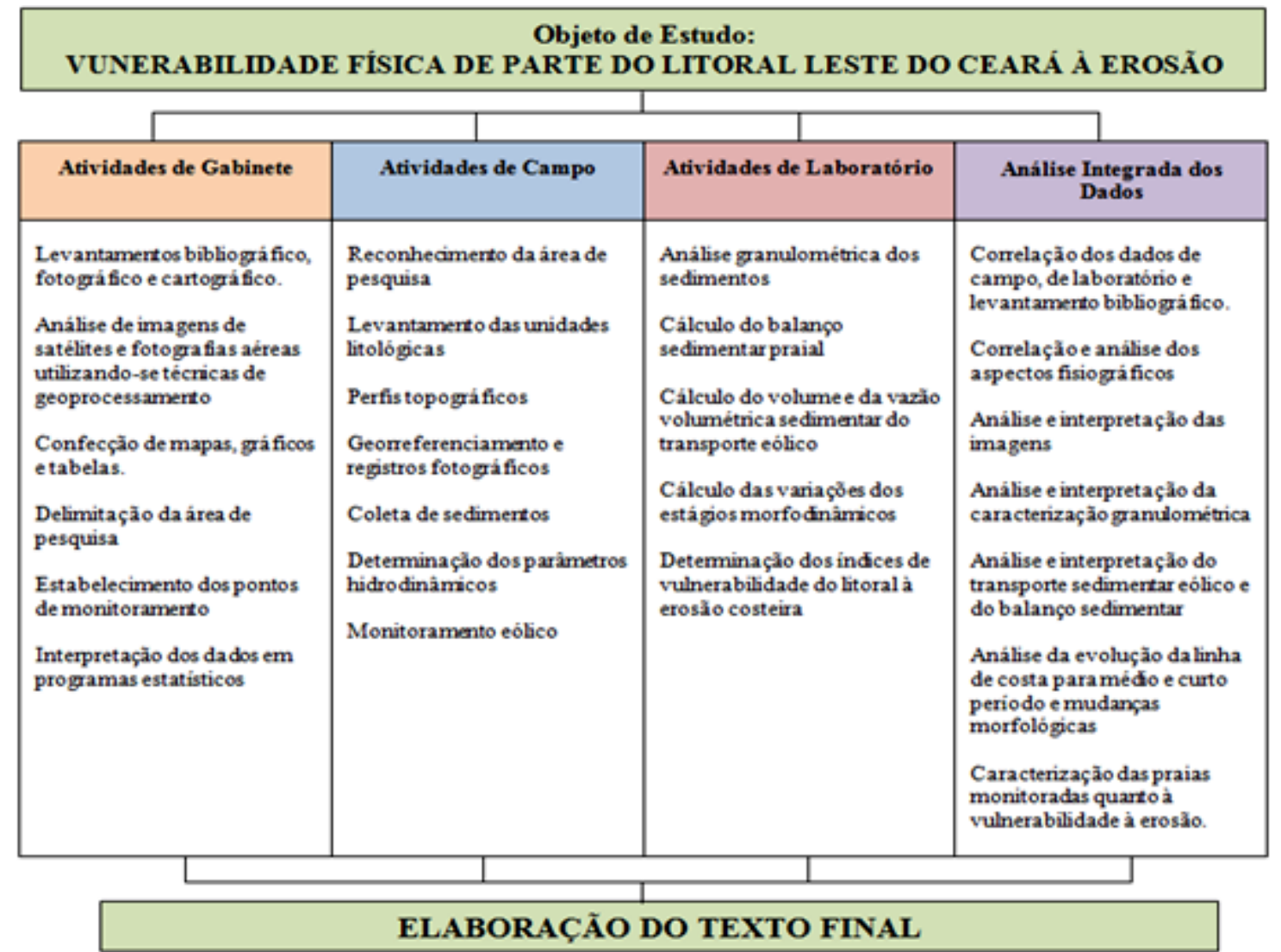

FIGURA 2 - Fluxograma da metodologia.

FONTE: Marino (2014). 
Seguindo-se a metodologia proposta por Mallmann \& Araújo (2010), segundo as variáveis e pesos descritos na Tabela 5, todos os dados referentes a cada segmento foram organizados em planilhas eletrônicas no programa Excel®Microsoft, nas quais os índices parciais e globais de vulnerabilidade (IPVs e IGVs) foram calculados.

Para integrar as variáveis, Mallmann e Araújo (2010) escolheram uma abordagem semiquantitativa, na qual todos os atributos, qualitativos ou quantitativos, foram codificados em pesos (1,2 e 3), de acordo com seu grau de influência sobre a vulnerabilidade da costa à erosão. Todos os dados referentes a cada segmento foram organizados em planilhas eletrônicas. Os índices parciais de vulnerabilidade foram calculados usando o algoritmo que consiste na raiz quadrada do produto das variáveis codificadas dividido pelo número de variáveis, conforme mostra a Equação (1).

$$
\begin{aligned}
& \mathrm{IPV}=\sqrt{(V 1 * V 2 * V 3 * \ldots V n / n)} \\
& \text { Onde: } \\
& \mathrm{v}=\text { variável } \\
& \mathrm{n}=\text { número de variáveis. }
\end{aligned}
$$

Mallmann \& Araújo (2010) integraram os IPVs no índice global de vulnerabilidade (IGV) a partir do seu somatório, Equação (2). E, para expressarem a vulnerabilidade em percentual, os valores finais do IGV foram divididos por um denominador comum, representado pelo somatório dos valores máximos possíveis de cada IPV.

$$
\mathrm{IGV}=\sum \mathrm{IPVs}
$$

Os valores calculados resultaram em números adimensionais, logo, elas acharam necessário um tratamento estatístico para sua interpretação. A partir do resultado desta análise, calcularam os quartis e estabeleceram a relação com o nível de vulnerabilidade para cada um dos índices parciais (Tabela 7).

TABELA 7 - Relação entre os intervalos dos valores e os graus de vulnerabilidade, segundo Mallmann e Araújo (2010).

\begin{tabular}{lc}
\hline \multicolumn{1}{c}{ Intervalo } & Grau de vulnerabilidade \\
\hline [Valor mínimo - Primeiro & Baixo \\
quartil (25\%)] & \\
] Primeiro quartil - Segundo & Moderado \\
quartil (50\%)] & Alto \\
] Segundo quartil - Terceiro & \\
quartil (75\%)] & Muito Alto \\
] Terceiro quartil - Valor & \\
máximo] Muito alto & \\
\hline
\end{tabular}

O grau de vulnerabilidade foi relacionado à variação da linha de costa, às feições morfológicas, às condições hidrodinâmicas, aos processos evolutivos, à estabilidade, à sedimentologia da praia e antepraia e às intervenções antrópicas, resultando na delimitação de setores ou células costeiras.

Para o levantamento da linha de costa atual e a coleta de informações foram conduzidas etapas de campo entre 2010 e 2011 por Marino (2014), e para médio período Marino \& Freire (2013) utilizaram a extensão Digital Shoreline Analysis System para o software ArcGIS 10.0, integrando dados georreferenciados, entre os anos de 1972 e 2010; entretanto, dividiram a área em quatro setores, conforme material, informações e resultados apresentados nas Tabelas 8 e 9. 
TABELA 8 - Material e informações utilizados para as análises em cada setor pesquisado, apresentados por Marino \& Freire (2013, p. 119).

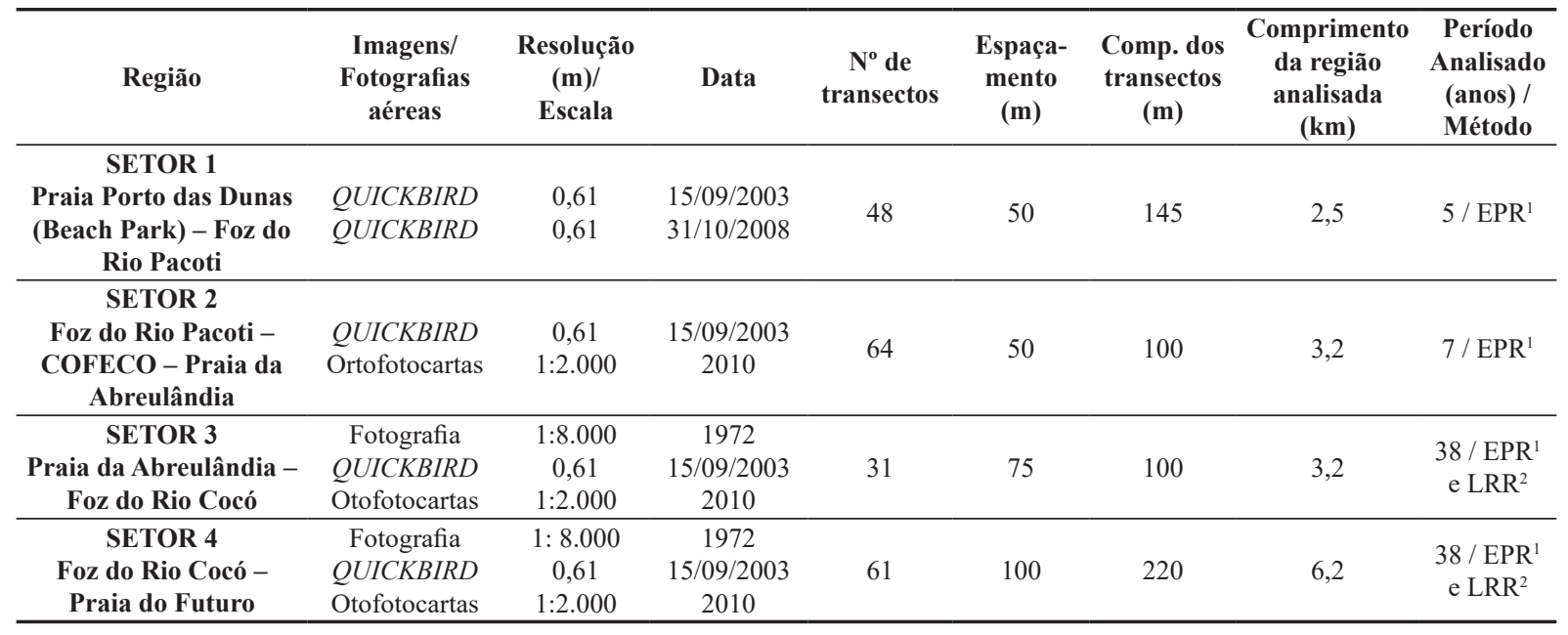

${ }^{1}$ Taxa do Ponto de Extremidade (EPR) / ${ }^{2}$ Regressão Linear Simples (LRR).

TABELA 9 - Dados gerais de variação da linha de costa expressos em taxas anuais e variação longitudinal ao longo dos perfis, por praias e de forma geral ( $\mu$ - valor médio; $\sigma$ - desvio padrão; Mín./Máx. - valores mínimos e máximos, respectivamente; valores positivos indicam deposição e negativos erosão), apresentados por Marino \& Freire (2013, p. 120).

\begin{tabular}{|c|c|c|c|c|c|c|}
\hline \multicolumn{7}{|c|}{ Taxa de Variação (m/ano) } \\
\hline \multirow[t]{2}{*}{ Setor } & \multirow[t]{2}{*}{$\begin{array}{l}\text { No de Tran- }^{\circ} \text { sectos } \\
\text { s }\end{array}$} & $\begin{array}{l}\text { Período } \\
\text { 1972-2010 }\end{array}$ & $\begin{array}{c}\text { Período } \\
1972-2003\end{array}$ & $\begin{array}{c}\text { Período } \\
\text { 2003-2008 }\end{array}$ & \multicolumn{2}{|c|}{$\begin{array}{l}\text { Período } \\
\text { 2003-2010 }\end{array}$} \\
\hline & & $\begin{array}{l}\mu \\
\operatorname{Min} / \operatorname{Max}\end{array}$ & Min/Max & Min/Max & $\begin{array}{c}\sigma \\
\mathbf{M} \\
\end{array}$ & Min/ \\
\hline $\begin{array}{l}\text { SETOR } 1 \text { - Praia Porto das Dunas (Beach Park) - } \\
\text { Foz do Rio Pacoti }\end{array}$ & 48 & - & - & $\begin{array}{l}-3,53 \pm 1,09 \\
-6,03 /-1,02\end{array}$ & \multicolumn{2}{|c|}{-} \\
\hline SETOR 3- Praia da Abreulândia - Foz do Rio Cocó & 31 & $\begin{array}{c}-0,07 \pm 0,11- \\
0,33 / 0,13\end{array}$ & $\begin{array}{c}0,05 \pm 0,15 \\
-0,19 / 0,29\end{array}$ & - & \multicolumn{2}{|c|}{$\begin{array}{c}-0,59 \pm 0,58- \\
2,25 / 0,35\end{array}$} \\
\hline SETOR 4 - Foz do Rio Cocó - Praia do Futuro & 61 & $\begin{array}{c}1,43 \pm 0,58 \\
0,23 / 3,09 \\
\end{array}$ & $\begin{array}{c}1,49 \pm 0,61 \\
0,24 / 3,26 \\
\end{array}$ & - & \multicolumn{2}{|c|}{$\begin{array}{c}1,02 \pm 1,86- \\
3,96 / 3,59\end{array}$} \\
\hline \multicolumn{7}{|c|}{ Variação da Linha de Costa (m) - Recuo (-) Avanço (+) } \\
\hline $\begin{array}{l}\text { SETOR } 1 \text { - Praia Porto das Dunas (Beach Park) - } \\
\text { Foz do Rio Pacoti }\end{array}$ & 48 & - & - & $\begin{array}{l}-17,67 \\
\pm 5,43\end{array}$ & - & \\
\hline $\begin{array}{l}\text { SETOR } 2 \text { - Foz do Rio Pacoti - COFECO - Praia da } \\
\text { Abreulândia }\end{array}$ & 64 & - & - & - & $-2,18$ & $\pm 6,56$ \\
\hline SETOR 3 - Praia da Abreulândia - Foz do Rio Cocó & 31 & $\begin{array}{l}-2,59 \\
\pm 4.07\end{array}$ & $\begin{array}{r}1,53 \\
\pm 4.61 \\
\end{array}$ & - & $-4,12$ & $\pm 4,09$ \\
\hline SETOR 4 - Foz do Rio Cocó - Praia do Futuro & 61 & $\begin{array}{r}54,33 \\
\pm 22.12 \\
\end{array}$ & $\begin{array}{r}46,14 \\
\pm 19.00\end{array}$ & - & 25,11 & $\pm 13,05$ \\
\hline
\end{tabular}


4. Características gerais das praias (células) analisadas

\subsection{Características do Setor 1 (Célula 1)- Praia Porto das Dunas}

Este setor, situado na praia Porto das Dunas, Célula 1, limite sudeste da área, à frente do ponto
P1, foi definido por apresentar uma retilineidade na morfologia do litoral, com direção SE-NW (Figura 3), com exceção de alguns cordões descontínuos de beachrocks paralelos à linha de costa, no estirâncio inferior.

A Célula 1, em frente ao condomínio Aquaville Resort, caracteriza-se pela presença de uma zona de pós-praia ocupada por alguns condomínios

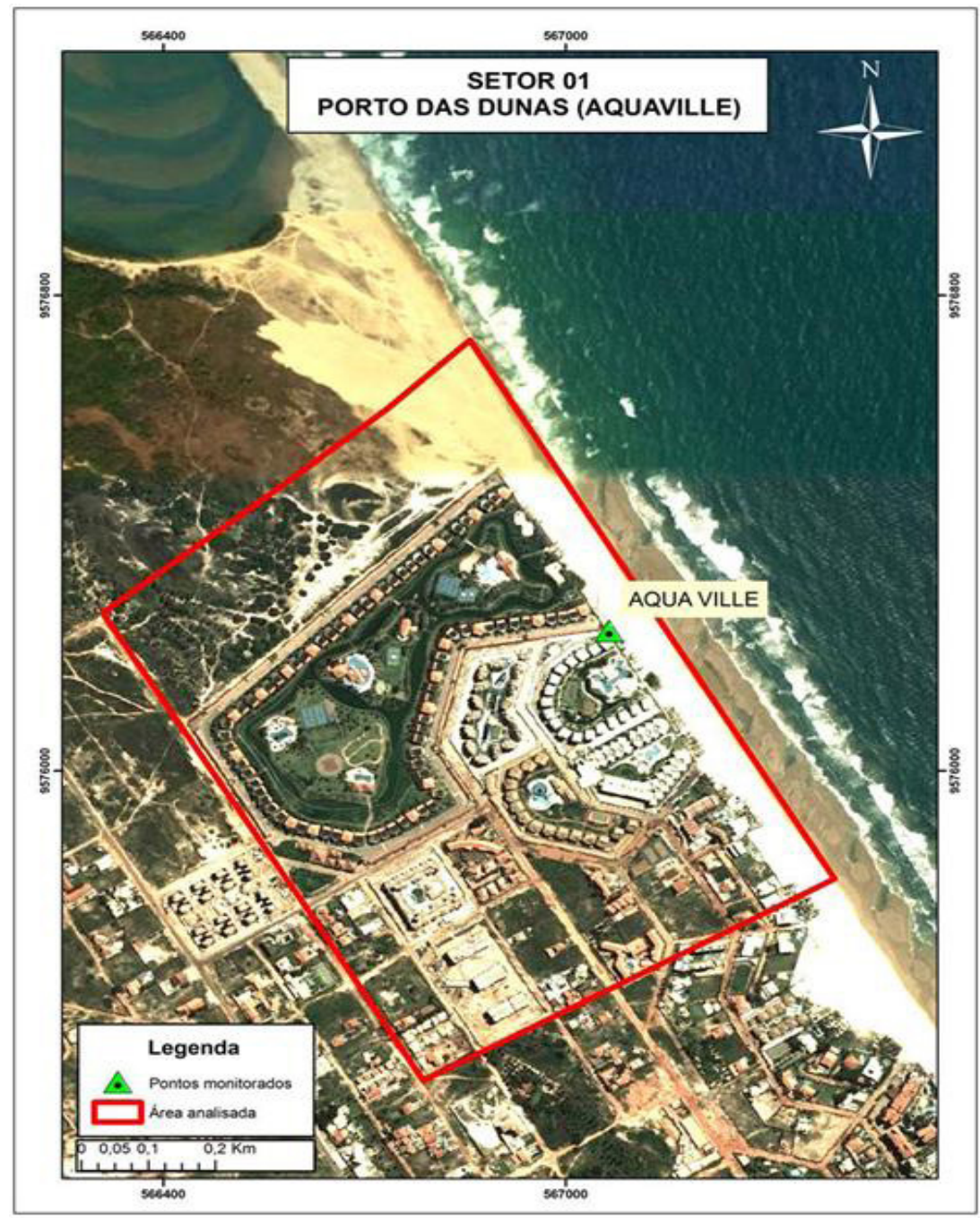

FIGURA 3 - Localização do Setor 1 e delimitação da Célula 1 (imagem Quickbird, 2003). FONTE: Marino (2014). 
turístico-hoteleiros e residenciais, zona de estirâncio desenvolvida e declividade média de $4,8^{\circ}$. Observa-se uma área do pós-praia preservada em alguns trechos, fixada por vegetação e apresentando, ainda, pequenas acumulações de origem eólica, dunas frontais.

De uma maneira geral, o Setor 1 revela um comportamento erosional predominante. A faixa praial deste setor é uma típica orla exposta, apresentando alto grau de exposição às ondas e nível de ocupação alto.

\subsection{Características e vulnerabilidade do Setor 2 - Praia da Abreulândia}

O Setor 2 abrange dois pontos monitorados no estudo, Praia da Abreulândia (COFECO), Perfil 2, e Praia da Sabiaguaba, Perfil 3, Células 2 e 3, respectivamente (Figura 4). Apresenta-se exposto a semiexposto às ondas, com nível de ocupação variando de baixo a médio, com expressivos índices de erosão para a Célula 2, ao longo do trecho estudado, e tendências máximas pontuais de acreção na Célula 3.

\subsubsection{Características da Célula 2-Praia da Abreulândia (COFECO)}

A Célula 2 encontra-se localizada à margem esquerda da desembocadura do rio Pacoti, registrando uma forte influência dos processos estuarinos. Apresenta uma zona de pós-praia pouco ocupada, com presença de berma e zona de estirâncio inclinada, na qual os estágios morfodinâmicos dos perfis praiais retratam uma extensão média de 61,82 metros e declividade média de $7,2^{\circ}$ no período monitorado. Registra-se a presença de rochas de praia, principalmente próximo à foz do rio Pacoti.
Esta Célula apresenta um equilíbrio dinâmico para os estudos morfodinâmicos de curto período (2010-2011) e uma tendência predominantemente erosional para um médio período (2003-2010). Esse processo, como já mencionado, pode tornar-se menos intenso, em razão da ocorrência do cordão descontínuo de beachrocks, os quais reduzem o poder erosivo das ondas.

\subsubsection{Características da Célula 3 - Praia da Abreulândia (Sabiaguaba)}

Corresponde à Praia da Sabiaguaba, na qual foi desenvolvido o monitoramento do Perfil 3, localizada à margem direita do rio Cocó.

A Célula 3 apresenta o grau de vulnerabilidade Baixo. Isto se deve ao estirâncio bem desenvolvido e com baixa declividade. Ocorre a presença de um extenso banco de beachrocks em toda a sua extensão, que proporciona um maior desenvolvimento da pós-praia e do estirâncio.

As análises efetuadas durante o monitoramento apresentaram para esta Célula uma feição acrecional para os intervalos de 38 anos (1972 a 2010) e de 7 anos (2003-2010) e erosional para o período de 31 anos (1972-2003). Considerando-se o monitoramento de curto prazo, agosto de 2010 a fevereiro de 2011, observou-se uma fase erosional, seguida de uma fase acrecional, dados registrados por Marino \& Freire (2013).

\subsection{Características do Setor 3}

Corresponde ao Setor compreendido entre a Praia do Caça e Pesca - Perfil 4, caracterizada como uma orla semiexposta a exposta, e Praia do Futuro - Perfil 5, orla exposta, localizado na porção noroeste da área de estudo (Figura 5). 


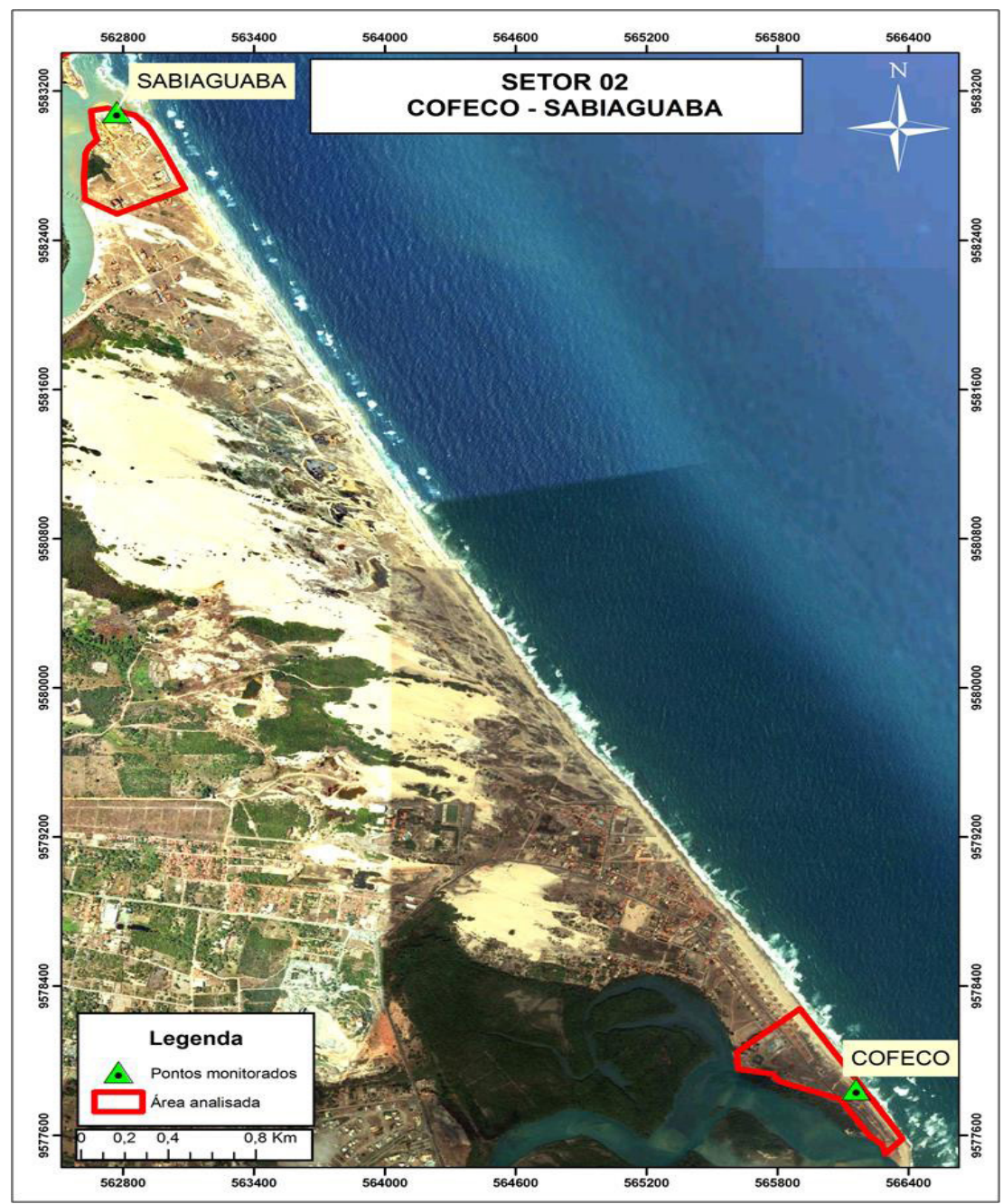

FIGURA 4 - Localização do Setor 2 e delimitação das Células 2 e 3 (imagem Quickbird, 2003). FONTE: Marino (2014).

Neste Setor, Marino \& Freire (2013) evidenciaram uma tendência generalizada de progradação de linha de costa em toda a sua extensão (Tabelas $8 \mathrm{e}$ 9), porém, apresenta um grande número de intervenções antrópicas (barracas de praia, hotéis, pousadas e segundas residências), alto grau de exposição às ondas e nível de ocupação variando de médio a alto, resultando em um grau de vulnerabilidade variando de Baixo a Médio. Este setor foi subdividido em duas células (Células 4 e 5).

\subsubsection{Características da Célula 4 - Praia do Caça e Pesca}

Esta Célula localiza-se à margem esquerda do rio Cocó, tendo sido definida por apresentar 


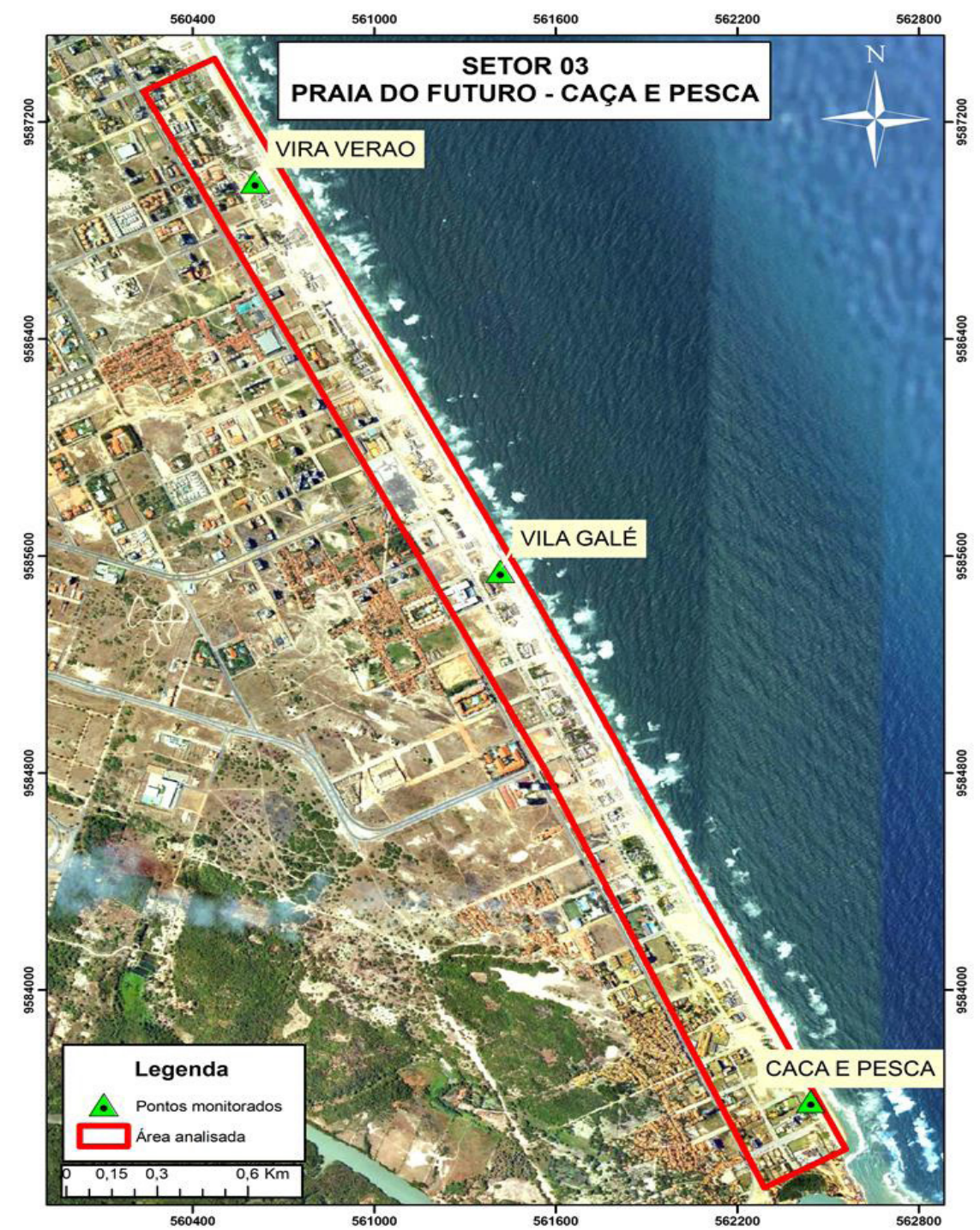

FIGURA 5 - Localização do Setor 3 e delimitação das células (imagem Quickbird, 2003). FONTE: Marino (2014).

influência direta do estuário desse rio. Encontra-se caracterizada por uma zona de pós-praia ocupada por estruturas urbanas (residências, hotéis e barracas de praia), com zona de estirâncio curta e presença de afloramentos das rochas de praia na zona de espraiamento inferior e na porção inicial da zona de surfe.

Segundo Marino \& Freire (2013), esta célula apresentou tendência ao equilíbrio para uma análise morfodinâmica de curto prazo (2010-2011). 
Já em relação às análises do monitoramento de médio período, esta Célula não sofreu alterações significativas, apresentando um comportamento progradacional (Tabelas 8 e 9).

\subsubsection{Características da Célula 5 - Praia do Futuro (Barraca Vira Verão)}

A Praia do Futuro apresenta a zona de pós-praia totalmente ocupada por estruturas fixas (barracas de praia, hotéis e prédios residenciais), zona de estirâncio curta e inclinação média de $3,4^{\circ}$.

A curva de tendência do volume de aporte de sedimentos, para o período de curto prazo monitorado, apresentou certo equilíbrio para o balanço sedimentar, com tendência acrecional, corroborando os dados para os períodos interdecadais analisados.

Durante o monitoramento eólico realizado na Praia do Futuro, o maior volume de sedimentos foi registrado na zona de pós-praia, entretanto, o bypass costeiro encontra-se quase completamente erradicado em função da urbanização associada ao crescimento da cidade de Fortaleza em direção leste.

As fontes de suprimento de sedimentos encontram-se todas localizadas a sudeste da Célula, como os campos de dunas, sedimentos fluviais dos rios Cocó e Pacoti, grãos desagregados dos bancos de rochas de praia, sedimentos da plataforma continental e das praias que são mobilizados pelas ondas e transportados pela deriva litorânea no sentido E-W, contribuindo para o processo acrecional nesta Célula.

O Espigão do Titanzinho, implantado no extremo NW desta Célula, interrompe as correntes de deriva litorânea, ocorrendo uma acumulação de sedimentos à barlamar da estrutura e erosão intensa à sotamar (litoral oeste do Estado do Ceará).

\section{Indicadores de erosão costeira}

Aplicando-se a metodologia desenvolvida por Souza (1997; 2001) e Souza \& Suguio (2003), integrada por Suguio et al. (2005), chegou-se aos indicadores de erosão costeira para as praias monitoradas, conforme resultados apresentados no Tabela 10.

A praia Porto das Dunas, litoral do município de Aquiraz, enquadrou-se em cinco dos indicadores analisados, apresentando maior destaque para os indicadores II e VIII, os quais tratam da retrogradação da linha de costa nas últimas décadas, da

TABELA 10 - Indicadores de erosão costeira das praias monitoradas, municípios de Aquiraz e Fortaleza (Tabela 1).

\begin{tabular}{|c|c|c|c|c|c|c|c|c|c|c|c|}
\hline $\begin{array}{c}\text { Indicadores de erosão costeira } \\
\text { (Souza, 1997, 2001; Souza \& Suguio, 2003). }\end{array}$ & I & II & III & IV & $\mathbf{V}$ & VI & VII & VIII & IX & $\mathbf{x}$ & XI \\
\hline \multicolumn{12}{|c|}{ PONTO DE MONITORAMENTO EM AQUIRAZ } \\
\hline PONTO 1 - PORTO DAS DUNAS (AQUAVILLE RESORT) & $\mathrm{X}$ & $\mathrm{X}$ & $\mathrm{X}$ & $\mathrm{X}$ & & & & $\mathrm{X}$ & & & \\
\hline \multicolumn{12}{|c|}{ PONTOS DE MONITORAMENTO EM FORTALEZA } \\
\hline PONTO 2 - PRAIA DA ABREULÂNDIA (COFECO) & $\mathrm{X}$ & $X$ & $\mathrm{X}$ & $\mathrm{X}$ & & $\mathrm{X}$ & & $\mathrm{X}$ & & & \\
\hline PONTO 3 - PRAIA DA SABIAGUABA & $\mathrm{X}$ & & $\mathrm{X}$ & $\mathrm{X}$ & & & & $\mathrm{x}$ & & & \\
\hline PONTO 4 - PRAIA DO CAÇA E PESCA & $\mathrm{X}$ & & $\mathrm{X}$ & $\mathrm{X}$ & & & & $\mathrm{x}$ & & & \\
\hline PONTO 5 - PRAIA DO FUTURO (BARRACA VIRA VERÃO) & $\mathrm{X}$ & & & & & & & $\mathrm{x}$ & & & \\
\hline
\end{tabular}

FONTE: Marino (2014). 
redução da largura da praia em toda a sua extensão e da construção e destruição de estruturas artificiais erguidas sobre os depósitos marinhos ou eólicos holocênicos que bordejam a praia, a pós-praia, o estirâncio e a face litorânea, corroborando os estudos desenvolvidos por Moura (2013).

Já as praias analisadas no município de Fortaleza foram divididas em três setores (Figura 1): a) praia da Abreulândia (COFECO), a qual foi enquadrada em seis dos onze indicadores, com maior destaque para II e VIII; b) as praias da Sabiaguaba e Caça e Pesca, estando enquadradas em quatro e três indicadores, respectivamente, destacando-se os itens IV e VIII, no que diz respeito principalmente às rochas de praia e às estruturas artificiais sobre os depósitos marinhos e eólicos; e c) a praia do Futuro, que enquadrou-se em apenas dois indicadores aplicados a esta metodologia, referentes aos tópicos I e VIII, registrando uma urbanização acelerada e desordenada em toda a faixa praial por inúmeras estruturas artificiais, tais como: barracas de praia, empreendimentos turístico-hoteleiros, prédios e casas residenciais, clubes recreativos e rodovias.

O litoral da área foi também analisado seguindo-se a metodologia proposta por Souza, C. (1997; 2001); Souza, M. (1999); Dominguez (1999); Souza \& Suguio (2003), integrada por Souza et al. (2005), Tabela 11, para classificar as praias quanto às causas naturais e antrópicas, aplicando-se treze índices (cor laranja) que sintetizam as causas naturais da erosão costeira e seus efeitos e processos associados, e sete índices (cor amarela) relacionados às causas antrópicas.

Esses índices apontaram conjuntos de fatores diferenciados para as praias estudadas (ver descritores dos índices na Tabela 2). A Praia da Sabiaguaba e a Praia do Caça e Pesca, adjacentes às desembocaduras dos rios Pacoti e Cocó, e a Praia do Futuro, na porção NW da área pesquisada, não apresentam processo de erosão dominante, fato confirmado pelos estudos e análises da morfodinâmica costeira de curto e médio períodos e das

TABELA 11 - Índices de causas naturais e antrópicas de erosão costeira das praias monitoradas, municípios de Aquiraz e Fortaleza (Tabela 2).

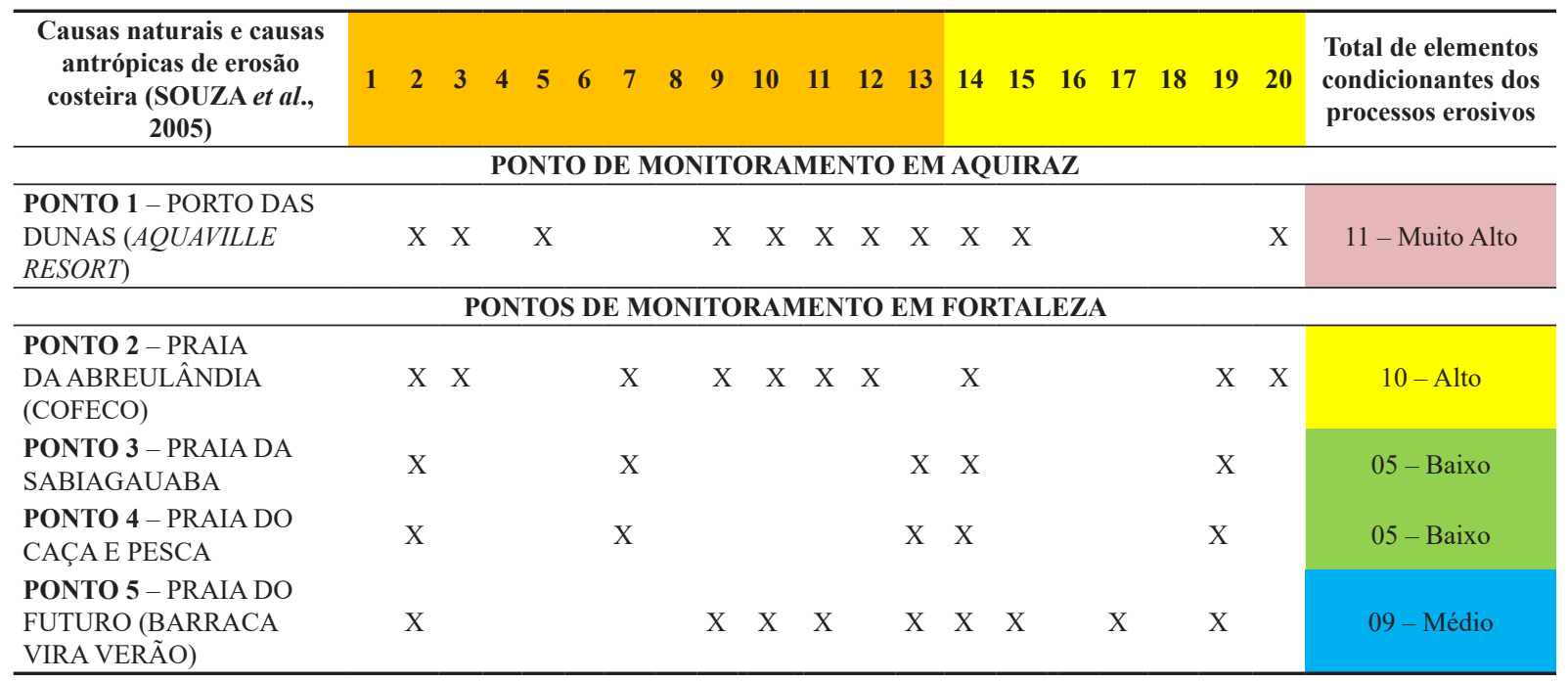

FONTE: Marino (2014). 
variações multitemporais nas desembocaduras dos rios supracitados. Ressalta-se a forte progradação da linha de costa na Praia do Futuro, principalmente em função do espigão do Titanzinho, e a proteção das praias do Caça e Pesca e da Sabiaguaba pelos cordões descontínuos das rochas de praia, dissipadores de energia das ondas incidentes, conforme Tabelas 8 e 9.

As praias Porto das Dunas e Abreulândia (COFECO) se encontram em processo de erosão, comprovado pelos dados registrados nos levantamentos de campo e laboratório de Marino \& Freire (2013), conformeTabelas 8 e 9 . Aponta-se ainda a ocupação da zona de pós-praia e dos campos de dunas.

Em relação aos índices de causas antrópicas, destacam-se principalmente: urbanização da orla com destruição de dunas e/ou impermeabilização de terraços marinhos, que eliminam os estoques sedimentares da praia e interferem na circulação de correntes costeiras, o que acarreta os processos erosivos diretos; retirada de areia de praias e dunas, que causa erosão em praias vizinhas (efeito dominó), alterando o balanço sedimentar das mesmas; conversão de manguezais, planícies fluviais e lagunares, e áreas inundadas em terrenos de urbanização e atividades antrópicas, modificações que causam desequilíbrio no balanço sedimentar; e, por último, tem-se o balanço sedimentar negativo decorrente de intervenções antrópicas.

Por meio do resultado desses indicadores de erosão costeira e da integração dos métodos diretos e indiretos, pode-se inferir um índice Muito Alto para a Praia Porto das Dunas, Alto para a Praia da Abreulândia (COFECO), Médio para a Praia do Futuro e Baixo para as praias da Sabiaguaba e Caça e Pesca.

\section{Características e vulnerabilidade das células costeiras}

Foram distinguidos três setores, subdivididos em células, num total de cinco, de acordo com suas características particulares e de ocupação, tomando-se como base as metodologias propostas por Dal Cin \& Simeoni (1994) e Projeto Orla (Brasil, 2006), que, à luz dessas discussões, consideraram três graus de vulnerabilidade: baixo, médio e alto (Tabela 12).

A Tabela 13 apresenta o resumo do checklist para o Índice de Vulnerabilidade (IPV) da faixa litorânea pesquisada, segundo Mallmann \& Araújo (2010), inferido por meio das cinco categorias analisadas: condições morfológicas, atributos naturais, influência marinha, processos costeiros e influência antrópica. A relação entre os intervalos dos valores e os graus de vulnerabilidade está representada na Tabela 14. Ressalta-se que esta análise foi efetuada na forma de comparação entre os setores analisados.

\subsection{Vulnerabilidade à erosão costeira - um desafio}

As taxas de avanço e de recuo da linha de costa, utilizando-se a extensão Digital Shoreline Data System - DSAS (Figura 6), integrando dados entre os anos de 1972 e 2010, registraram para o trecho praia Porto das Dunas até a margem esquerda do rio Pacoti um estágio erosivo, taxa de variação média de -3,53m/ano e - $17,67 \mathrm{~m}$ em 5 anos; entre a foz do rio Pacoti e a praia da Abreulândia, índices de erosão média de - $0,31 \mathrm{~m} /$ ano e - $2,18 \mathrm{~m}$ em 7 anos; da praia da Abreulândia até a desembocadura do rio Cocó uma tendência erosional média de $-0,07 \mathrm{~m} /$ ano e $-2,59 \mathrm{~m}$, em 38 anos, caracterizando uma estabilidade nesse setor, provavelmente, devido ao 
TABELA 12 - Características e vunerabilidade à erosão costeira dos setores que compõem a área pesquisada.

\begin{tabular}{|c|c|c|c|c|c|c|}
\hline Setor/Ponto & Exposição & $\begin{array}{c}\text { Fisiografia e } \\
\text { Geomorfologia }\end{array}$ & $\begin{array}{c}\text { Sistemas } \\
\text { associados }\end{array}$ & Características & $\begin{array}{c}\text { Inclinação } \\
\text { Média do } \\
\text { Estirâncio }\end{array}$ & Vulnerabilidade \\
\hline $\begin{array}{c}\text { SETOR 1 } \\
\text { PONTO } 01 \\
\text { PRAIA PORTO } \\
\text { DAS DUNAS } \\
\text { (AQUAVILLE } \\
\text { RESORT) }\end{array}$ & Alta & Orla exposta & $\begin{array}{l}\text { Campo de } \\
\text { dunas, foz } \\
\text { do rio Pacoti } \\
\text { e cordão de } \\
\text { beachrocks } \\
\text { próximo à } \\
\text { foz e em } \\
\text { alguns pontos } \\
\text { isolados }\end{array}$ & $\begin{array}{l}\text { Presença de uma zona de } \\
\text { pós-praia ocupada por alguns } \\
\text { condomínios turístico- } \\
\text { hoteleiros e residenciais), zona } \\
\text { de estirâncio desenvolvida e } \\
\text { comportamento erosional }\end{array}$ & $4,8^{\circ}$ & Muito Alta \\
\hline $\begin{array}{c}\text { SETOR 2 } \\
\text { PONTO 02 } \\
\text { PRAIA DA } \\
\text { ABREULÂNDIA } \\
\text { (COFECO) } \\
\\
\text { PONTO 03 } \\
\text { PRAIA DA } \\
\text { SABIAGUABA }\end{array}$ & $\begin{array}{l}\text { Média a } \\
\text { alta }\end{array}$ & $\begin{array}{c}\text { Orla } \\
\text { semiexposta a } \\
\text { exposta }\end{array}$ & $\begin{array}{l}\text { Foz do rio } \\
\text { Pacoti, campo } \\
\text { de dunas e } \\
\text { cordão de } \\
\text { beachrocks } \\
\text { próximo à foz }\end{array}$ & $\begin{array}{l}\text { Zona de pós-praia pouco } \\
\text { ocupada, com presença de } \\
\text { berma e zona de estirâncio } \\
\text { inclinada e tendência } \\
\text { predominante erosional } \\
\text { Zona de pós-praia com } \\
\text { ocupação média, apresentando } \\
\text { estirâncio bem desenvolvido, } \\
\text { com baixa declividade, } \\
\text { processos costeiros variando } \\
\text { de erosional a deposicional, } \\
\text { tendência ao equilíbrio. }\end{array}$ & $7,2^{\circ}$ & $\begin{array}{l}\text { Alta } \\
\text { Baixa }\end{array}$ \\
\hline $\begin{array}{c}\text { SETOR 3 } \\
\text { PONTO 04 } \\
\text { PRAIA DO CAÇA } \\
\text { E PESCA } \\
\text { PONTO 05 } \\
\text { PRAIA DO } \\
\text { FUTURO } \\
\text { (BARRACA VIRA } \\
\text { VERÃO }\end{array}$ & $\begin{array}{l}\text { Média a } \\
\text { alta }\end{array}$ & $\begin{array}{c}\text { Orla } \\
\text { semiexposta a } \\
\text { exposta }\end{array}$ & $\begin{array}{l}\text { Foz do } \\
\text { rio Cocó, } \\
\text { complexo } \\
\text { de dunas e } \\
\text { cordão de } \\
\text { beachrocks } \\
\text { próximo à foz }\end{array}$ & $\begin{array}{l}\text { Zona de pós-praia ocupada por } \\
\text { estruturas urbanas (residências, } \\
\text { hotéis e barracas de praia), } \\
\text { com zona de estirâncio curta e } \\
\text { tendência progradacional. } \\
\text { Zona de pós-praia totalmente } \\
\text { ocupada por estruturas fixas } \\
\text { (barracas de praia, hotéis e } \\
\text { prédios residenciais), zona de } \\
\text { estirâncio curta e inclinada, } \\
\text { tendência progradacional. O } \\
\text { bypass costeiro acha-se quase } \\
\text { completamente erradicado em } \\
\text { função da urbanização. }\end{array}$ & $3,0^{\circ}$ & Baixa \\
\hline
\end{tabular}

FONTE: Marino (2014).

cordão descontínuo de rochas de praia paralelo à costa; a Praia do Futuro uma tendência fortemente progradante, média de $+1,43 \mathrm{~m} /$ ano e $+54,33 \mathrm{~m}$, em 38 anos, alimentada pela erosão das praias situadas à barlamar e também dos beachrocks localizados nas desembocaduras dos rios Pacoti e Cocó, além dos sedimentos transportados pelos mesmos e dos campos de dunas. As areias resultantes são transportadas até o espigão do Titanzinho, que impede a continuidade do transporte e propicia o intenso acúmulo de sedimentos (Marino, 2014). 
TABELA 13 - Resumo dos índices de causas naturais e antrópicas de erosão costeira das praias monitoradas, municípios de Aquiraz e Fortaleza.

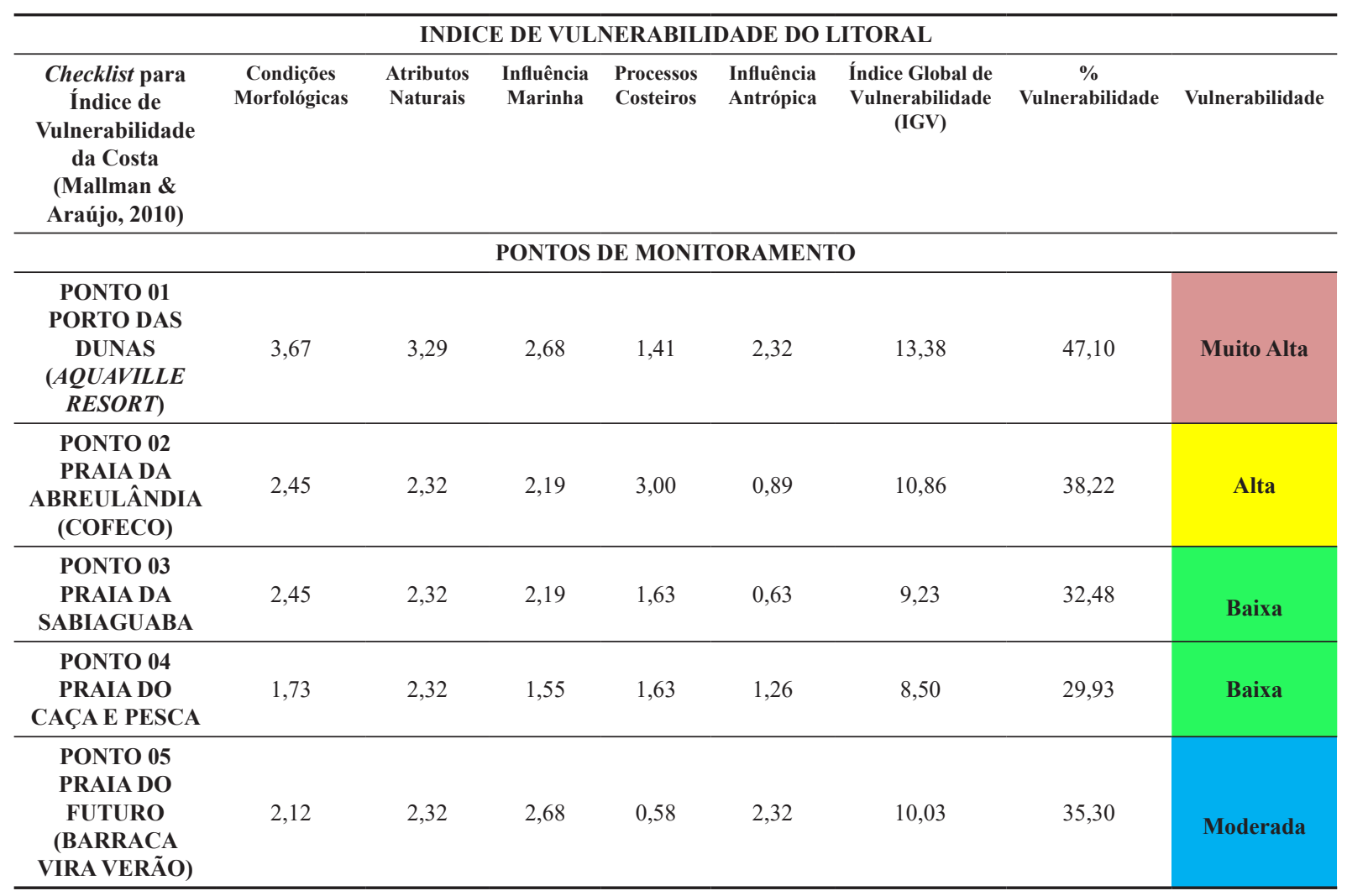

FONTE: Marino (2014).

TABELA 14 - Relação entre os intervalos dos valores e os graus de vulnerabilidade entre os setores analisados.

\begin{tabular}{lccc}
\hline \multicolumn{1}{c}{ Intervalo } & Valor & Percentual & Grau de vulnerabilidade \\
\hline [Valor mínimo - Primeiro quartil (25\%)] & 9,23 & 32,48 & Baixo \\
] Primeiro quartil - Segundo quartil (50\%)] & 10,03 & 35,30 & Moderado \\
] Segundo quartil - Terceiro quartil (75\%)] & 10,86 & 38,22 & Alto \\
] Terceiro quartil - Valor máximo] Muito alto & 13,38 & 47,10 & Muito Alto \\
\hline
\end{tabular}

FONTE: Marino (2014). 


\section{Praia Porto das Dunas (Beach Park) até a desembocadura do rio Pacoti}

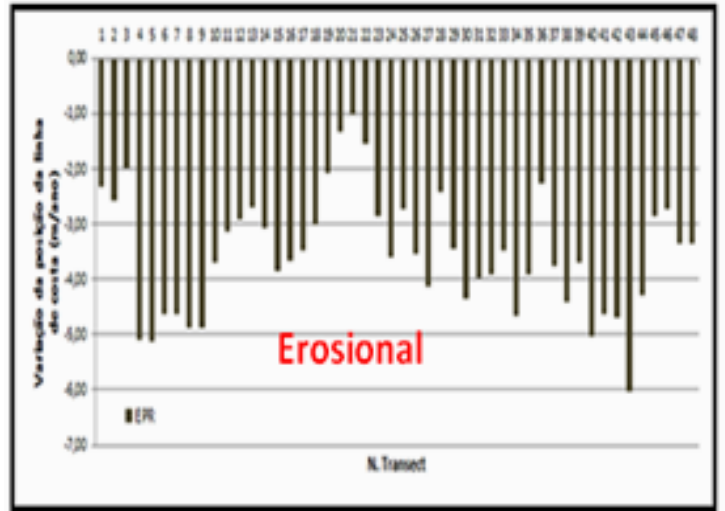

Praia da Abreulândia até a desembocadura do rio Cocó

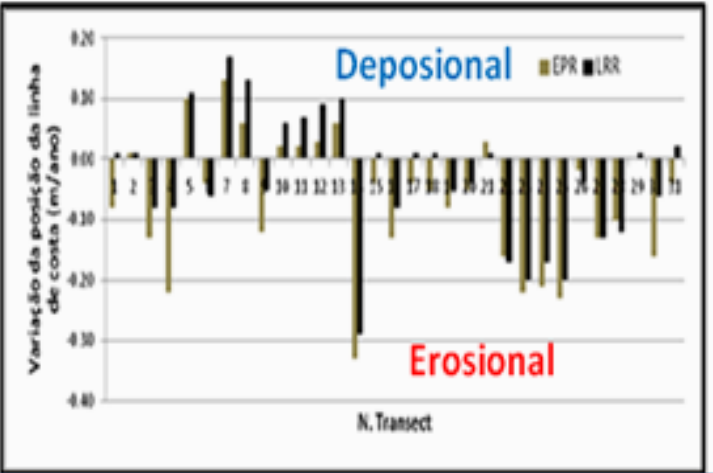

Desembocadura do rio Pacoti, COFECO até a Praia da Abreulândia
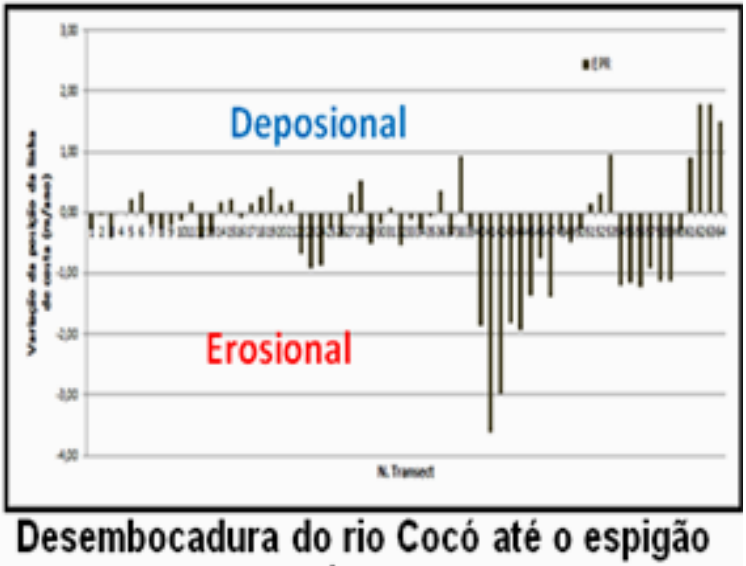
do Titanzinhol(Praia do Futuro)

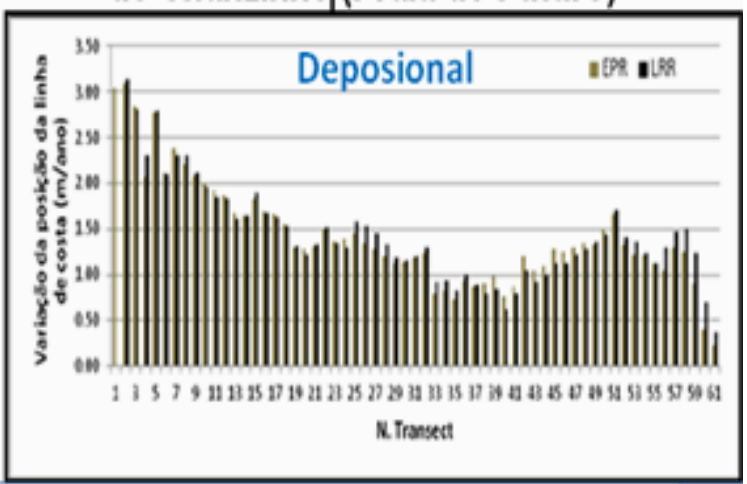

FIGURA 6 - Aplicação da ferramenta DSAS para a região costeira entre a Praia Porto das Dunas até o espigão do Titanzinho, extremo oeste da Praia do Futuro. A numeração indica cada transecto. FONTE: Marino (2014).

Evidenciou-se, por meio dos levantamentos, das análises efetuadas e dos estudos comparativos com pesquisas desenvolvidas por outros pesquisadores, na área e em regiões circunvizinhas, que a tendência generalizada de déficit de sedimentos está relacionada à ocupação indevida e concentrada, principalmente nas zonas de pós-praia e campo de dunas, impedindo o trânsito e o aporte de sedimentos supridores desses ambientes.
Observou-se que o processo de urbanização está bastante acelerado e ocorre de forma desorganizada, sem levar em consideração as características e fragilidades dos ecossistemas costeiros, como a ocupação das zonas de bypass, fato que influencia diretamente na sazonalidade natural de remoção e deposição de sedimentos arenosos.

Diversas formas de uso e ocupação do solo, tais como: barramentos dos cursos fluviais, supres- 
são da mata ciliar, impermeabilização dos campos de dunas, construção de grandes empreendimentos imobiliários, residenciais e turístico-hoteleiros na planície de deflação e zona de pós-praia, abertura de vias de acesso, têm resultado no desequilíbrio da dinâmica costeira, alterando fortemente o suprimento de sedimentos arenosos para a faixa praial.

Estas áreas necessitam da integração de estudos específicos, os quais possibilitem compreender as condições e processos impressos, atualmente, sobre o seu capital natural (recursos naturais + serviços naturais), no intuito de buscar soluções para minimizar os problemas encontrados decorrentes do mau uso e ocupação, com a finalidade de chegar a um equilíbrio ambiental, primordial para o desenvolvimento sustentável aliado ao socioambiental e econômico.

Recomenda-se uma fiscalização mais rigorosa e a implantação de programas de monitoramento por parte dos órgãos ambientais sobre esses ecossistemas, no intuito de minimizar a pressão sobre o capital natural. Deve-se respeitar as áreas de preservação permanente (APPs), principalmente às margens dos rios Pacoti e Cocó, áreas de grande importância ao equilíbrio dinâmico costeiro da região. A fiscalização em relação às dunas, áreas de preservação permanente, deve ser bem mais rigorosa, já que por lei são áreas não edificáveis. Na região pesquisada, pode-se observar que houve danos às mesmas para implantação de construções, além da supressão da vegetação protetora e fixadora dessas dunas, em alguns casos, chegando-se à supressão total do corpo dunar.

Nas áreas de preservação ambiental (APAs), a exemplo da APA do rio Pacoti, admite-se a construção de unidades multifamiliares, conjuntos habitacionais, hotéis, clubes e assemelhados, mediante licenciamento prévio da Superintendência Estadual do Meio Ambiente - SEMACE, uma vez que tenha sido precedido da realização de um estudo de impacto ambiental, examinadas as alternativas locacionais, avaliadas as suas consequências ambientais e indicadas as restrições e medidas consideradas necessárias à salvaguarda do ecossistema da APA. Porém, deve-se vetar a possibilidade de se construir nas Áreas de Preservação Permanente - APPs - dentro da APA do rio Pacoti.

As APPs na área de estudo, ao longo dos rios Pacoti e Cocó, devem ser especialmente protegidas, pois apresentam as funções ambientais de preservar os recursos hídricos, a paisagem, a biodiversidade e proteger o solo. Os fiscais dos órgãos ambientais, em parceria com a comunidade local, devem providenciar as comunicações de crimes ambientais ao Ministério Público para serem adotadas as medidas nas esferas penal e civil.

Deve-se impedir a expansão urbana sem um plano de ordenamento territorial, ou seja, respeitando as suas fragilidades ambientais, buscando um uso e uma ocupação pautados nas suas potencialidades, sendo necessários levantamentos e pesquisas mais detalhados quanto a esses fatores.

\section{Conclusão}

A avaliação do grau de vulnerabilidade à erosão costeira realizada por meio da associação dos indicadores propostos por Dal Cin \& Simeoni (1994), Mallmann \& Araújo (2010) e Projeto Orla (Brasil, 2006), bem como características, dados e análises efetuadas, assinalou um panorama diversificado para os três setores pesquisados, relacionado às feições e aos tipos de uso das células delimitadas.

Os resultados obtidos demonstram que áreas que apresentam grau de vulnerabilidade muito alto coincidem com as células e setores mais urbanizados, sugerindo um controle muito mais antrópico do que natural sobre a vulnerabilidade. 
Ademais, foi possível identificar as variáveis de maior influência sobre a vulnerabilidade física de cada célula, estando relacionadas: à morfologia costeira, aos processos costeiros, à influência antrópica e aos atributos e dinâmica naturais.

Estas áreas necessitam da integração de estudos específicos, os quais possibilitem compreender as condições e os processos atuantes, atualmente,

\section{Referências}

Albuquerque, M. G. Estádios morfodinâmicos e sua relação com os riscos de banho de mar na praia do Futuro, Ceará. In: Anais do Congresso Brasileiro de Oceanografia. Vitória, 6 de abr., 2005.

Anders, F. J.; Byrnes, M. R. Shore and Beach: Accuracy of shorelines change rates as determined from maps and aerial photographs. Shore and Beach, 59(1), 17-26, 1991. Disponível em: <http://www.asbpa.org/pdfs/aTableof Contents.pdf $>$.

Arcinfo Gis 10.0. Software Teaching Lab Pak ArcInfo 10. Sistema Microsoft Windows 2000, XP 32 e 64 bits e 2003: Arc Editor-ESRI. Versão 10.0, idioma: pt. 2010. CD ROM.

Bird, E. C. F. Coastline Changes: a global review. Chichester: John Wiley - Interscience, 1985.

Bird, E. C. F. Beach management. Chichester: John Wiley, 1996.

Brasil. Ministério do Exército, Superintendência do Desenvolvimento do Nordeste. Folha SA-24-Z-C-V. Diretoria do Serviço Geológico.Região Nordeste do Brasil (Aquiraz). Índice de nomenclatura. 1 mapa. Escala 1:100.000. Recife: SUDENE, 1971.

Brasil. Ministério do Meio Ambiente, Ministério do Planejamento, Orçamento e Gestão. Projeto Orla: fundamentos para gestão integrada, 2006. Disponível em: <http://www.mma. gov.br/estruturas/orla/_arquivos/11_04122008111238.pdf>. Acesso em: 06 dez. 2011.

Bruun, P. Sea level rise as a cause of shoreline erosion. Journal of Waterways and Harbor Division, 88(1), 117130, 1962. sobre o seu capital natural, no intuito de buscar soluções para minimizar os problemas encontrados decorrentes do mau uso e da ocupação, com a finalidade de chegar a um equilíbrio ambiental. A partir dos resultados obtidos, a sua aplicação pode vir a orientar o processo de ocupação das praias pesquisadas, tendo em vista que na maior parte delas a urbanização é acelerada e desordenada.

Bush, D. M.; Neal, W.; Young, R.; Pilkey, O. Utilization of geoindicators for rapid assessment of coastal-hazard risk and mitigation. Ocean and Coastal Management, 42(8), 647-670, 1999. doi: 10.1016/j.coastaleng.2008.10.003

Callaghan, D. P.; Ranasinghe, R.; Short, A. Quantifying the storm erosion hazard for coastal planning. Coastal Engineering: An International Journal for Coastal, Harbour and Offshore Engineers, 56(1), 90-93, 2009. doi: 10.1016/j. coastaleng.2008.10.003

Camfield, F.; Morang, A. Defining and interpreting shoreline change. Ocean and Coastal Management, 32(3), 129151, 1996. doi: 10.1016/S0964-5691(96)00059-2

Crowell, M.; Leatherman, S. P.; Buckley, M. K. Historical shoreline change: error analysis and mapping accuracy. Journal of Coastal Research, 7(3), 839-852, 1991.

Dal Cin, R.; Simeoni, U. A model for determining the classification, vulnerability and risk in the southern coastal zone of the Marche (Italy). Journal of Coastal Research, 10(1), 18-29, 1994.

Dias, J. M. A. A evolução actual do litoral português. Geonovas, 11, 15-28, 1990. Disponível em: <http://w3.ualg. pt/ jdias/JAD/papers/ RN/ 90_Geonovas_AD.pdf $>$.

Dillenburg, S.; Esteves, L. S.; Tomazelli, L. A critical evaluation of coastal erosion in Rio Grande do Sul, Southern Brazil. Anais da Academia Brasileira de Ciências, 76(3), 611-623, 2004. doi: 10.1590/S0001-37652004000300014

Dolan, R.; Hayden, B.; Heywood, J. A new photogrammetric method for determining shoreline erosion. Coastal Engineering, 2, 21-39, 1978. doi: 10.1016/0378-3839(78)90003-0 
Dominguez, J. M. L. Erosão costeira na região leste-nordeste do Brasil. Salvador, Tese (Doutorado em Geociências) - UFBA, 1999.

Dominguez, J. M. L. Avaliação regional do problema da erosão na região nordeste do Brasil. 2007. Disponível em: $<$ http://www.cpgg.ufba.br/lec/eros.htm>.

Esteves, L. S.; Finkl, C. W. The problem of Critically Eroded Areas (CEA): an evaluation of Florida beaches. Journal of Coastal Research, 26, 11-18, 1998.

Google Earth. Software google earth. Sistema operacional Microsoft Windows (6.1.7601.1). 2010. Disponível em: $<$ http://www.google.com.br/earth/download/ge/agree.html >.

Harvey, N.; Clouston B.; Carvalho P. Improving coastal vulnerability assessment methodologies for integrated coastal zone management: an approach from South Australia. Australian Geographical Studies, 37(1), 50-69, 1999.

Lins-de-Barros, F. M. Risco e vulnerabilidade à erosão costeira no município de Maricá, Rio de Janeiro. Rio de Janeiro, Dissertação (Mestrado em Geografia) - UFRJ, 2005.

Maia, L. P.; Freire, G. S. S.; Pessoa, P. R. S.; Rodrigues, A. C. B.; Magalhães, S. H. O.; Araújo, P. S. A. Transporte de sedimentos na região costeira do Ceará. Fluxo de sedimentos e características granulométricas. In: Anais do Simpósio de Geologia do Nordeste. Fortaleza, 19 de nov., 1997.

Mallmann, D. L. B. Vulnerabilidade do litoral sul de Pernambuco à erosão. Recife, Dissertação (Mestrado em Oceanografia) - UFPE, 2008.

Mallmann, D. L. B.; Araújo, T. C. M. de. Vulnerabilidade física do litoral sul de Pernambuco à erosão. Tropical Oceanography, 38(2), 130-152, 2010. Disponível em: <http:// www.revista.ufpe.br/tropicaloceanography/artigos_completos_resumos_t_d/38_2010_2_2_mallmann.pdf $>$.

Marino, M. T. R. D. Análise integrada dos aspectos geoambientais e da dinâmica costeira de médio e curto período da planície litorânea entre as praias do Futuro e Porto das Dunas, Ceará, Brasil. Fortaleza, Tese (Doutorado em Geologia) - UFC, 2014.

Marino, M. T. R. D.; Freire, G. S. S. Análise da evolução da linha de costa entre as praias do Futuro e Porto das Dunas, Região Metropolitana de Fortaleza (RMF), estado do Ceará, Brasil. Revista Gestão Costeira Integrada, 13(1), 113-129, 2013. doi: $10.5894 /$ rgci373
Marino, M. T. R. D.; Freire, G. S. S.; Horn Filho, N. O. Aspectos geológicos e geomorfológicos da zona costeira entre as praias do Futuro e Porto das Dunas, região metropolitana de Fortaleza, Ceará, Brasil. Revista de Geologia, 25(1), 77-96, 2012. Disponível em: <http://www.periodicos. ufc.br/index.php/geologia/article/view/1342>.

Marino, M. T. R. D.; Freire, G. S. S.; Horn Filho, N. O. Variações granulométricas ao longo da costa da região metropolitana de Fortaleza, Ceará, Brasil. Revista da Gestão Costeira Integrada, 13(3), 267-282, 2013. doi: 10.5894/rgci411

Martins, L. R.; Tabajara L. L.; Ferreira, E. R. Linha de Costa: problemas e estudos. Revista Gravel, 2, 40-56, 2004.

Moraes, A. C. R. Contribuições para a gestão da zona costeira do Brasil: elementos para uma geografia do litoral brasileiro. 2. ed., ampl. São Paulo: Annablume, 2007.

Morais, J. O de. Processos e impactos ambientais em zonas costeiras. Revista de Geologia da UFC, 9, 191-142, 1996.

Moura, M. R. Processos costeiros e evolução da ocupação nas praias do litoral oeste de Aquiraz, Ceará entre 19702008. Fortaleza, Dissertação (Mestrado em Geografia) - UFC, 2009.

Moura, M. R. Dinâmica costeira e vulnerabilidade à erosão do litoral dos municípios de Caucaia e Aquiraz, Ceará. Fortaleza, Tese (Doutorado em Geografia) - UFC, 2012.

Moura, M. R. Evolução da linha de costa na praia do Icaraí, Caucaia, Ceará, Brasil. In: Anais do Congresso da Associação Brasileira de Estudos do Quaternário. Natal, 4 de ago., 2013.

Moura, M. R.; Oliveira, G. G. de; Morais, J. O. de. Tendências de erosão da linha de costa, associada às mudanças na morfodinâmica praial do município de Caucaia-Ceará. In: Anais do Seminário do Dia do Geógrafo. Fortaleza: 14 de jun., 2007.

Muehe, D. Caracterização físico-natural da plataforma continental interna e área costeira adjacente. In: Macrodiagnóstico da Zona Costeira do Brasil na escala da União. Ministério do Meio Ambiente, dos Recursos Hídricos e da Amazônia Legal, 1996a. p. 83-100.

Muehe, D. Geomorfologia costeira. In: Guerra, A. J. T.; Cunha, S. B. (Org.). Geomorfologia: exercícios, técnicas e aplicações. Rio de Janeiro: Bertrand, 1996b. p. 191-238. 
Muehe, D. Critérios morfodinâmicos para o estabelecimento de limites da orla costeira para fins de gerenciamento. Revista Brasileira de Geomorfologia, 2(1), 35-44, 2001. doi: 10.20502/rbg.v2i1.6

Muehe, D. Aspectos gerais da erosão costeira no Brasil. Revista Mercator - Revista de Geografia da UFC, 4(7), 97-110, 2005.

Muehe, D. (Org.). Erosão e progradação no litoral brasileiro. Brasília: Ministério do Meio Ambiente, 2006.

Muehe, D. Erosão costeira - tendência ou eventos extremos? O litoral entre Rio de Janeiro e cabo Frio, Brasil. Revista da Gestão Costeira Integrada, 11(3), 315-325, 2011. doi: 10.5894/rgci282

Pinheiro, L. S. Compatibilização dos processos morfodinâmicos e hidrodinâmicos com o uso e ocupação da praia da Caponga-Cascavel-CE. Fortaleza, Dissertação (Mestrado em Geografia) - UECE, 2000.

Short A. D.; Trembanis, A. C. Decadal scale patterns in beach oscillation and rotation Narrabeen beach, Australia times series, PCA and wavelet analysis. Journal of Coastal Research, 20(2), 523-532, 2004.

Sousa, P. H. G. de O. Dinâmica ambiental e transformações socioespaciais da orla maritima de Paracuru - Ceará. Fortaleza, Dissertação (Mestrado em Geografia) - UECE, 2007.
Souza, C. R. G. As células de deriva litorânea e a erosão nas praias do estado de São Paulo. São Paulo, Tese (Doutorado em Geociências) - USP, 1997.

Souza, C. R. G. Coastal erosion risk assessment, shoreline retreta rates and causes of coastal erosion along the state of São Paulo coast, Brazil. Revistas de Pesquisas em Geociências, 28(2), 459-474, 2001. Disponível em: <http://www. ufrgs.br/igeo/pesquisas/28-2.html>.

Souza, C. R. G; Suguio, K. The coastal erosion risk zoning and the São Paulo State Plan for Coastal Management. Journal of Coastal Research, 35, 530-547, 2003.

Souza, C. R. G (Ed.); Suguio, K.; Santos, A. M. dos; Oliveira, P. E. Quaternário do Brasil. Ribeirão Preto: Holos, 2005.

Souza, M. C. Mapeamento da planície costeira e morfologia e dinâmica das praias do município de Itapoá, Estado de Santa Catarina: subsídios à ocupação. Curitiba, Dissertação (Mestrado em Geologia) - UFPR, 1999.

Tagliani, C. R. A. Técnicas para avaliação da vulnerabilidade ambiental de ambientes costeiros utilizando um sistema geográfico de informações. In: Anais do Simpósio Brasileiro de Sensoriamento Remoto. Belo Horizonte: 10 de abr., 2003.

Thieler, E. R.; Hammar-Klose, E. S. National assessment of coastal vulnerability to sealevel rise, Preliminary Results for the U. S. Atlantic Coast, 1999. Disponível em: <http:// pubs.usgs.gov/of/1999/of99-593/>. 